\title{
Gender Wage Differences in West Germany: A Cohort Analysis ${ }^{1}$
}

\author{
Bernd Fitzenberger ${ }^{2}$ and Gaby Wunderlich ${ }^{3}$
}

\author{
October 2000
}

\begin{abstract}
:
A comprehensive descriptive analysis of gender wage differences over a long time period is missing for West Germany. Using an empirical approach which takes into account explicitely changes of wage distributions for both males and females as well as lifecycle and birth cohort effects, we go beyond conventional decomposition techniques of the average gender wage gap. The paper provides some stylized facts of the level and dynamics of the gender wage gap from 1975 - 1995. The empirical analysis is based upon the IAB-Beschäftigtenstichprobe. Our findings confirm the importance of distributional effects relating to skill level and employment status. While life-cycle wage growth is in general much lower for females compared to males, comparing their estimated time trends implies that the gender wage gap has narrowed substantially in the lower part of the wage distribution especially for low- and medium-skilled females but much less so in the upper part of the wage distribution. Surprisingly, we do not find any cohort effects for wages of female employees.
\end{abstract}

Keywords: Gender Wage Gap, Quantile Regression, Cohort Analysis

JEL Classification: J16, J31, J71

\footnotetext{
${ }^{1}$ This paper is part of the research project "Holen die Frauen auf? Ein Vergleich von Erwerbsverhalten, Beschäftigung und Verdiensten deutscher und britischer Frauen im Zeitverlauf" at the Centre of European Economic Research (ZEW). We thank the Hans-Böckler-Stiftung for financial support. We are grateful for useful suggestions and comments received at the "International Conference on Economic Implications of Quantile Regressions" (June 2000 in Konstanz), the "Annual Meeting of the German Economic Association" (September 2000 in Berlin), and at the Seminar of the Department of Labor Economics, Human Resources, and Social Security at ZEW.

${ }^{2}$ Prof. Bernd Fitzenberger, Ph.D., University of Mannheim, Department of Economics, 68131 Mannheim. E-mail: bernd.fitzenberger@vwl.uni-mannheim.de.

${ }^{3}$ Gaby Wunderlich, Centre for European Economic Research (ZEW), Department of Labor Economics, Human Resources, and Social Policy, 68161 Mannheim, L7,1. E-mail: wunderlich@zew.de.
} 


\section{Contents}

1 Introduction $\quad 1$

2 Data 3

3 Descriptive Evidence $\quad 5$

4 Empirical Framework $\quad 8$

4.1 Characterization of Wage Profiles .............. 8

4.2 Testing for Uniform Wage Growth . . . . . . . . . . . . . 9

4.3 Empirical Implementation .................. 11

4.4 Quantile Regression Approach ............... 13

4.5 Block Bootstrap Procedure for Inference . . . . . . . . . . 14

5 Empirical Results $\quad \mathbf{1 5}$

5.1 Estimated Specifications for Wage Equations . . . . . . . . . . 15

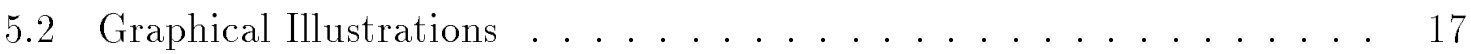

6 Conclusions $\quad 21$

$\begin{array}{llr}7 & \text { Appendix } & 24\end{array}$

8 References $\quad 36$ 


\section{Introduction}

The wage structure in West Germany is often alleged to be fairly stable and, although growing, labor force participation of women is still lower than in many other OECD countries. ${ }^{4}$ At the same time, the formal skill level of the German work force is improving very quickly with disproportionate gains for women. Finally, a lot of political and social efforts have been undertaken to promote labor market chances of female workers. Therefore, it is of great interest to investigate empirically the change of wage differences between male and female workers. Using the IAB-Beschäftigtenstichprobe, a large micro data set for the time period from 1975 to 1995 , this paper provides a comprehensive descriptive analysis of the level and the dynamics of the gender wage gap across the entire wage distribution taking into account life-cycle and birth cohort effects.

Based on limited survey data, international comparative studies generally find a slowly but steadily declining gender wage gap in mean wages for West Germany (Blau and Kahn 1996, Joshi and Paci 1998). ${ }^{5}$ Focussing on Germany Prey (1999) and Lauer (2000) also find that the gender wage gap is slightly decreasing and they emphasize that the gender specific wage distribution in West Germany has not at all been stable during the last decades. Therefore, the movements of the entire wage distributions of males and females have to be taken into account (Blau and Kahn 1996, 1997). It is not clear if wage distributions for different types of workers change in the same way. Using data from the GSOEP (German Socio Economic Panel), Prey (1999) concludes that the decline in the gender wage gap represents disproportionate wage growth in the lower part of the wage distribution for both males and females (a related argument is made by Hunt (1997) for East Germany). For the time period from 1975 to 1990 , Fitzenberger (1999, chapter 2) finds that, both overall as well as within groups of the same formal skill level, wage dispersion has increased for full-time working males and decreased for full-time working females. At the same time, a much stronger trend towards skill upgrading is observed for females compared to males.

Our brief review of the literature reveals that a comprehensive descriptive analysis of gender wage differences for West Germany over a long time period is missing. Such an analysis should go beyond decomposition techniques which are mostly restricted to "explain" gender specific differences in mean wages. The observation of differences in wage growth at different points of the wage distribution suggests a more detailed analysis. Such distributional effects could explain why decomposition exercises are often plagued by identifying strong counteracting effects which are associated with fairly small aggregate changes (Prey 1999, Lauer 2000). Our intention is to investigate the differences in the wage distributions for male and female workers of the same age and the same formal skill level and how these differences change over time.

\footnotetext{
${ }^{4}$ In 1995 the labor force participation rate of women (age 25-54) amounts to $73.2 \%$ and the employment-population ratio to $67.6 \%$, see OECD (1999).

${ }^{5}$ In contrast, Weiler (1997) presents descriptive evidence that gender specific wage differentials in West Germany have not changed since 1978. Her analysis is based on data from German official statistics for groupings in pay schedules according to the formal requirements of a job. It is not straight forward to relate these wage data to the evidence based on individual data.
} 
In particular, our analysis addresses the following issues:

- How do wages differ over the life-cycle between male and female workers? Do women benefit less from wage growth over the life-cycle possibly due to interruptions in the accumulation of human capital during the child rearing phase or due to the lack of career possibilities?

- If orientations of women have changed towards a higher labor force participation and higher formal skill levels, one should observe a narrowing gender wage gap. Such changes are likely to have a stronger effect on regular full-time jobs compared to part-time jobs. In addition, birth cohort effects on female wages could be operating such that younger cohorts benefit disportionately from a reduction of the gender wage gap since younger cohorts have better chances to obtain higher formal skill levels and are more work-oriented. ${ }^{6}$

- If social efforts (e.g. union policies) to improve the relative earnings of women result in an improvement of the relative wage position of female workers (reduction of the gender wage gap), it would again be likely that those policies have a stronger effect on regular full-time jobs compared to part-time jobs since the latter are less institutionally regulated. Do women in part-time jobs experience a reduction in the gender wage gap to the same extent as women in full-time jobs?

- Do the data confirm that the disproportionate increase of the formal skill level of females is associated with a reduction of the gender wage gap?

The empirical strategy of the paper is to estimate a parsimonious descriptive model describing life-cycle, birth cohort, and time effects on wages. Various tests are performed as to whether cohort effects exist and whether time trends are uniform across the wage distribution. The differences in the estimated time trends are interpreted as changes in the gender wage gap between male and female workers of the same age and the same formal skill level. Our findings should be viewed as stylized facts on the gender wage gap in West Germany over the time period from 1975 to 1995. Despite the descriptive nature of the analysis, our findings contradict some simple hypotheses regarding the nature and the dynamics of the gender wage gap.

Our main results are the following: (i) We do not find cohort effects for wages of female workers. (ii) In general, wage trends for part-time working females are quite different from full-time working females. (iii) For all types of workers, we can identify a uniform time trend across all birth cohorts. (iv) Contrasting the estimated time trends, the gender wage gap has narrowed substantially in the lower part of the wage distribution for full- and part-time working females (especially for low- and mediumskilled women). Wage trends have been much less beneficial for high-skilled females. (v) Wage growth over the life-cycle is much lower for females compared to males (it may even be negative in the lower part of the wage distribution) and the life-cycle profiles

\footnotetext{
${ }^{6}$ For cohort effects on wages of West German females see Boockmann/Steiner (2000) and Steiner/Lauer (2000). Their results are not directly comparable to ours because of different data and methods.
} 
appear not to have changed over time. (vi) Our findings confirm the importance of distributional effects.

The remainder of the paper is structured as follows. Section 2 describes the data ("IAB-Beschäftigtenstichprobe") used for the empirical analysis. Some basic descriptive evidence on the gender wage gap in the entire distribution is presented in section 3. Our empirical framework to test for uniformity of wage trends and to identify cohort effects is developed in section 4. Making use of this framework, section 5 describes the main empirical results obtained in this paper. As a conclusion, section 6 interprets the empirical results. The final appendix comprises tables and figures referred to when discussing the empirical results.

\section{Data}

Our analysis is based on the new release of the $\mathrm{I}_{\mathrm{A}} \mathrm{BS}$ ("IAB-Beschäftigtenstichprobe") for the time period from 1975 to 1995 for West Germany. The $\mathrm{I}_{\mathrm{A}} \mathrm{BS}$ is a $1 \%$ random sample from German social security accounts which has only recently been made available by the research institute of the Federal Employment Service ("Institut für Arbeitsmarkt- und Berufsforschung") in Nürnberg. The main features of the data set and a users' guide can be found in Bender et al. (1996). ${ }^{7}$ Social security contributions are mandatory for employees who earn more than a minimum wage threshold and who are working regularly. The main exceptions are civil servants who do not pay any social security contributions. Further exclusions from the mandatory contributions are students who work less than 20 hours a week on a regular basis or less than 6 weeks full-time. About $80 \%$ of the German employees are covered by this mandatory pension system.

We restrict the analysis to workers who are between 25 and 55 years old to avoid interference with unfinished education and early retirement. Workers are grouped by their skills according to the following formal education levels given in the $\mathrm{I}_{\mathrm{A}} \mathrm{BS}$ :

(U) without a vocational training degree

(M) with a vocational training degree

(H) with a technical college ("Fachhochschule") or a university degree

$$
\begin{array}{r}
(\text { low-skilled }) \\
(\text { medium-skilled }) \\
\text { (high-skilled) }
\end{array}
$$

There are quite a number of missings for the skill variable in the data (around $3.3 \%$ of all employment spells for males, $3.7 \%$ for full-time females, and $7.5 \%$ for part-time females). However, these missings can be reduced using the skill information recorded in previous spells of the same individual or, if information from previous spells is not available, in future employment spells assuming that the skill level does not change after the age of 25 years. This correction reduces the share of employment spells with

\footnotetext{
${ }^{7}$ This guide describes the first release of the $\mathrm{I}_{\mathrm{A}} \mathrm{BS}$ comprising the time period 1975 to 1990 . The construction of the data set is basically the same for the two time periods.
} 
missing skill information to $2.13 \%$ for males, $2.52 \%$ for full-time females, and $6.1 \%$ for part-time females.

The dataset does not include information on hours worked. However, one can distinguish between full-time and part-time employment and, for spells in part-time employment, it is recorded whether the hours of work are either less (三less or equal) or more than half of the regular working time. Regarding gender and employment status, we consider three groups of workers:

- full-time working males,

- full-time working females, and

- females working part-time,

as it turns out that only a negligeable proportion of males is working part-time. For females working part-time, we also record in each cell the share of those working less than half of the regular working time.

From the $\mathrm{I}_{\mathrm{A}} \mathrm{BS}$, we construct wage and employment information by cells defined by skill, gender, and employment status. The basic information in the $\mathrm{I}_{\mathrm{A}} \mathrm{BS}$ consists of social security insurance spells comprising the starting point and the end of an employment spell and the average daily gross wage (excluding employers' contributions). The daily gross wage is censored from above and truncated from below. If the wage is above the upper social security threshold ("Beitragsbemessungsgrenze"), the daily social security threshold is reported instead. If the wage is below the lower social security threshold, the employee does not have to pay social security contribution and therefore, does not appear in the data. The level of both thresholds changes annually. A wage below the lower threshold level implies that employment is only part-time and typically much less than half of the regular working time.

Because of censoring from above, we use quantiles of daily gross wages. For our analysis, an annual wage observation is calculated as the weighted average of the wage observation of the individual for all spells within one year where the spell length is used as the weight. For the subsequent calculations, the annual wage observation is weighted by the total employment spell length as percentage of the whole year. These weights are used to calculate the $20 \%-, 50 \%-$, and $80 \%$-quantiles of wages - as long as these quantiles are not censored - and raw employment weights for all individuals in cells defined by skill group, gender, employment status, age, or year. With multiple spells (jobs) at the same time, cf. Bender et al. (1996, p. 74), we take the sum of the daily wages across spells as the wage observation and treat the individual as full-employed. Without referring to this every time in this study, real wages are deflated by the price index for aggregate private consumption.

A problem of the data is the structural break in wages between 1983 and 1984, cf. Steiner and Wagner (1998). Over time, the income components being subject to social security tax were extended, cf. Bender et al. (1996, p. 15). In particular, starting in 1984 one-time payments to the employee had to be taxed. Steiner and Wagner note that this results in a considerable spurious increase in earnings inequality due to the structural 
break in the data. To correct for this problem, we use the procedure suggested in Fitzenberger (1999, appendix). This procedure estimates the spurious wage increase in the upper part of the wage distribution between 1983 and 1984. Then, individual wages before 1984 are corrected based on the position of each worker in the marginal distribution of wages.

\section{Descriptive Evidence}

This section presents the basic trends in wages for full-time working males, and for full-time and part-time working females over the time period from 1975 to 1995 . At this point, we develop an overall picture about wage trends over this period. Therefore we do not control for participation changes and composition bias, which are presumably serious problems for females in general and even more for part-time working females.

Figure 1 (see appendix for graphical illustrations) depicts wage trends for men as well as for full- and part-time working women at three quantiles $(20 \%, 50 \%$, and $80 \%)$ of the unconditional wage distribution. The results include observations with missing skill information but there are basically no changes if missings are excluded. It is clearly visible that $\log$ real wages of males and females exhibit a different trend from 1975 to 1995 (see graphs to the right of figure 1 for growth rates of $\log$ real wages).

The increasing inequality of the male wage distribution contrasts sharply to the nearly constant or even slightly decreasing inequality for females. The difference between the $20 \%$ - and the $80 \%$-quantile of the male wage distribution increases over time and has grown by $15 \%$ in 1995 compared to 1975 . Most of the increase in inequality occurs in the upper part of the distribution. While men face increasing inequality, full-time working females experience a compression. They gain most at the $20 \%-q u a n t i l e$, resulting in a decrease of inequality from below, and both the median and $80 \%$-quantile move in a nearly parallel fashion. A slightly different picture emerges for the case of female parttimers. The $80 \%$-quantile starts to grow disproportionately in the middle of the 1980's - whereas during the time before the $20 \%$-quantile grows fastest. Thus the trend for female part-timers has reversed from wage compression until 1985 to increasing inequality afterwards.

The growth rate of $\log$ real wages is almost highest for males at the $80 \%$-quantile (35\%), but wage growth of the lowest quantile of full-time working females is even a little bit higher than the wage growth of the highest quantile of full-time males and also that of part-time females. The graphs show further that males in the lower part of the distribution experienced the lowest wage growth of about $20 \%$ and $25 \%$ respectively, whereas the $20 \%$-quantile of full-time women exhibits the strongest rise in real wage of approximately $36 \%$. As far as the $80 \%$-quantiles of the female wage distributions are concerned, it is obvious that their wage growth differs, if at all, only slightly from the growth of the $80 \%$-quantile of the male wages.

The first impression is therefore that, on the one hand, the unconditional wage distribution of men became more unequal while the distribution of full-time females became more compressed, and that, on the other hand, the lower quantiles of full- and part- 
time working women catched up over time compared to the wage development of males in the lower part of the distribution.

It will be investigated next to what extent the unconditional wage distributions absorb wage differences by the aforementioned skill levels: low-skilled (U), medium-skilled $(\mathrm{M})$, and high-skilled (H).

A restriction of the data is the censoring of the daily wage at the social security threshold which is particularly important for high-skilled males. In this case, it is not possible to plot the $\log$ real wages for the $50 \%$ - and $80 \%$-quantiles. For highskilled full-time females the $80 \%$-quantile is censored as well, but only for the first seven years of the observation period. Furthermore, we do not put much emphasis on high-skilled part-time working women because of the heterogeneity and the highly irregular wage patterns for that group.

The development, which we have seen in unconditional log real wages, varies much more if we control for skill level (figure 2, figure 3). For males, inequality is clearly related to skill level. The higher the skill level, the higher the increase in inequality. The picture for full-time females looks somewhat different: Wages have been growing very strongly at the $20 \%$-quantile of low- and medium-skilled female full-timers. The message is the same for female part-timers: Here we find a disproportionate increase of wages at the $20 \%$-quantile of the high-skilled and increasing inequality of wages for medium- and low-skilled female part-timers since the middle of the 1980's. Summing up, we find compression in the case of female full-timers (U) and (M) as well as female part-timers $(\mathrm{H})$ and increasing inequality for males in general, female part-timers (U) and $(\mathrm{M})$ as well as full-timers $(\mathrm{H})$.

The graphs show additionally that in general wage growths for all groups is positive over the 20 years as a whole but that all plots have a more or less pronounced pattern or cyclical "megatrend" in common: the growth rate of real wages is positive from 1975 to 1980 , nearly constant or even negative until 1985 and again positive until approximately 1991/92. Then follows again a short period of stagnation and afterwards a further increase. Especially for the first 10 to 15 years of the observed time period this pattern is more or less visible in almost all plots.

Real wages increase over time at all quantiles and it is apparent that for (1) mediumskilled men from 1975 until 1995 and (2) part-time working women as well as (3) lowskilled men from the end of the 1980's on, the growth of real wages is higher at higher quantiles. Thus, there is a trend towards higher overall inequality in wages. But while this development is not very strong both for low- and medium-skilled female parttimers, for whom inequality rose only slightly between the $50 \%$ - and $80 \%$-quantiles, it is most relevant for medium-skilled males over the whole period (and probably for the high-skilled because the wage growth of the $20 \%$-quantile of those males is the lowest of all groups and the upper quantiles are at least as high as the social security threshold). The opposite has happened for female full-timers at low and medium skill level. While for medium-skilled full-time females the distribution from the beginning in 1975 became steadily more equal, this trend started in the middle of the 1980's for the low-skilled.

These findings are, at least for men, in sharp contrast to findings in OECD (1993, 
1996) for West Germany based on the German Socioeconomic Panel (see also Steiner and Wagner (1998) and Möller (1999)). The OECD studies argue that during the second half of the 1980's wage inequality was slightly decreasing and this compression continued into the 1990 's. Our results are quite close in spirit to the findings in Blau and Kahn (1996), who argue that there is substantially more compression of wages at the bottom of the wage distribution in countries like West Germany compared to the United States due to different institutional settings. From a dynamic perspective, it is quite conceivable that a trend towards higher inequality in West Germany is mitigated in the lower part but not in the upper part of the distribution.

The important question to be asked is whether and by how much female wages have catched up compared to male wages over time. Figure 4 offers descriptive evidence that low- and medium-skilled female full- and part-timers mainly in the lower part of the wage distribution have made some gains. The figure shows the difference in log real wage growth between women and men of the same skill group at the same quantiles of the wage distribution. High-skilled females are compared to medium-skilled males due to censoring of wages in the case of high-skilled males.

The picture is twofold: from 1975 until the early 1980's women lose some ground or cannot improve their wage position very much in almost all cases. In 1985 we see on average a $5 \%$ loss for low- and medium-skilled full- and part-timers, except at the 20\%-quantile, compared to 1975. The loss of high-skilled full-and part-timers is even worse and amounts to nearly $15 \%$ in the extreme. In the mid 1980 's there seems to be a turnaround. The trend is mostly positive after $1985 / 86$ so that, in most cases, the status quo of 1975 can be reestablished or exceeded, respectively. As far as the whole time span is concerned the strongest improvement is found at the $20 \%$-quantile. The gain at the $20 \%$-quantile amounts to almost $10 \%$ for low-skilled full- and part-time working women, and medium-skilled working women compared to men of the same skill level. Fulltime working women of medium skill level improved their position a little bit more than $10 \%$. The same pattern shows up at the $50 \%$-quantile but on a lower level of nearly $5 \%$. For high-skilled women, full- and part-timers, the picture is worse. Summig up the trends for all quantiles of full- and part-timers, except for the 20\%-quantile of the part-timers, one can state that all seem to be worse off in 1995 than in 1975 in spite of the upward trend starting in the middle of the 1980's.

Low skilled female part-timers show the most uniform development over all quantiles compared to the other groups. Those women lost in the first half of the observation period $5 \%$ but catched up by $10 \%$ in the second half.

Summarizing, one can conclude that there has been a rise in overall wage inequality from 1975 to 1995 for men, but a compression of the distribution for women. However, these changes in inequality have not at all been uniform. Quite complex changes can be observed within and across skill groups and across males and females of different employment status. Therefore our subsequent analysis tries to shed more light on the wage trends across and within skill groups separately for men and full-time and part-time working women. We will investigate how much of the observed changes can be attributed to composition effects. Furthermore, we will show how wage positions of women have changed over time in direct comparison to male workers by means of comparing their estimated macro time trends. 


\section{Empirical Framework}

This section presents the empirical framework to investigate the movement of the entire wage distribution for synthetic cohorts over time. A cohort is defined by the year of birth of the worker. Regarding the rising labor force participation rates of females, it is often argued that the behavior of females has changed such that younger cohorts are more attached to the labor market.

In order to decompose between- and within-shifts in the wage distribution, we estimate various quantile regressions. Testing for uniformity across cohorts and across quantiles for given cohorts allows to investigate, whether the entire wage distribution has shifted uniformly over time. Alternatively, it could be the case that wage trends differ across cohorts indicating the presence of "cohort effects" and by quantiles indicating a trend towards increasing or decreasing within group wage dispersion. Under certain conditions, as will be made precise in the following, a cohort effect designates a movement of the entire life-cycle wage profile for a given cohort relative to other cohorts. In providing a parsimonious representation of trends in the entire wage distribution, we are able to pin down precisely the differences in wage trends across groups of workers defined by gender, skill level, and employment status. Basing the estimates on all years of observation, we are not restricted to a pointwise comparison of onedimensional summary measures of average wage differences in two particular years as it is often done in the literature. In light of the descriptive evidence presented in the previous section, we explicitly take into account the possibility that wage differences are sensitive to the business cycle as well as that they differ by age and by the position in the wage distribution.

Due to the inherent identification problem between age, cohort, and time effects on wages, see Heckman and Robb (1985), wage profiles based on cross-section relationships between age and wages over a sequence of years and movements of life-cycle wage profiles faced by successive cohorts are statistically indistinguishable. However, considering the wage growth experienced by a particular cohort over time or over age (both movements are of course the same), it can be tested whether apart from the differential age effect different cohorts exhibit the same time trend.

The basic version of the empirical framework described in this section was first developed by MaCurdy and Mroz (1995) for the context of trends in median wages for male workers in the United States. Variants of this framework are applied in Fitzenberger et al. (1995) for West Germany and in Gosling et al. (1996) for the UK. Fitzenberger (1999, chapter 3 ) extends the framework to study uniformity of wage trends across the entire distribution in the context of estimating quantile regressions for full-time working males in West Germany based on a shorter time period than considered in this study.

\subsection{Characterization of Wage Profiles}

We denote the age of an employee by $\alpha$ and the calendar time by $t$. A cohort $c$ can be defined by the year of birth. The variables age, cohort and calendar year are linked 
by the relation $t=c+\alpha$. Studies of wage trends often investigate movements of "age-earnings profiles" 8

$$
\ln [w(t, \alpha)]=f(t, \alpha)+u
$$

The deterministic function $f$ measures the systematic variation in wages and $u$ reflects cyclical or transitory phenomena. For a fixed year $t$, the function $f(t, \alpha)$ yields the conventional cross-section wage profiles. Movements of $f$ as a function of $t$ describe how cross-section wage profiles shift over time. The cross-sectional relation $f$ as a function of age does not describe "life-cycle" wage growth for any cohort or, put differently, the cross-section relation may very well be the result of "cohort effects". In fact, "cohort-earnings profiles" are statistically indistinguishable from "age-earnings profiles". Wage profiles can also be expressed as a function of cohort and age

$$
g(c, \alpha) \equiv g(t-\alpha, \alpha) \equiv f(t, \alpha)
$$

where the deterministic function $g$ describes how age-earnings profiles differ across cohorts. Holding age constant, $g(c, \alpha)$ describes the profiles of wages earned by different cohorts over time. Holding the cohort constant yields the profile experienced by a specific cohort over time and age. The latter is referred to as the "life-cycle profile", because it reflects the wage movements over the life-cycle of a given cohort. Again this profile reflects two effects such that life-cycle wage growth due to aging and intertemporal shifts in wages are indistinguishable.

The different parameterizations $g(c, \alpha)$ and $f(t, \alpha)$ are equivalent representations of the same wage profile. Without further assumptions, "pure life-cycle effects" due to aging or "pure cohort effects" cannot be identified. Focusing on wage trends for a given cohort over time, we use the cohort representation of wage profiles as the perspective of our analysis.

\subsection{Testing for Uniform Wage Growth}

Our analysis investigates whether wage trends are uniform across cohorts in the sense that every cohort experiences the same time trend in wages and the same age-specific wage growth. The latter can be attributed to labor market experience and is interpreted here as a life-cycle effect. Despite the identification issues discussed above, the existence of a uniform time trend across cohorts is a testable implication in the framework presented here. If such a uniform time trend is found, it is designated as the macroeconomic wage trend for the group of workers considered. ${ }^{9}$ However, as will be seen from the empirical results reported in the following, these uniform time trends differ by skill level, gender, and employment status.

Two notions of wage growth prove useful: First, wage growth for a given cohort in the labor market over time ("Insider Wage Growth"), and second, wage growth over time experienced by successive cohorts when entering the labor market ("Entry Wage

\footnotetext{
${ }^{8}$ Alternatively, researchers often describe trends in "experience-earnings profiles". Basically, the identification issue discussed in the following also applies to potential experience being constructed as "age - years of schooling -6 ".

${ }^{9}$ If no uniform trend is found, the average across age groups combines age, time, and cohort effects.
} 
Growth"). Insider wage growth is given by

$$
\left.\frac{\partial g}{\partial t}\right|_{c}=\left.\frac{\partial g}{\partial \alpha}\right|_{c} \equiv g_{\alpha}(c, \alpha) \equiv g_{\alpha}
$$

comprising the simultaneous change of time and age. Alternatively, holding age constant yields the change of wages earned by different cohorts at specific ages. For the age at labor market entry, $\alpha_{e}$, entry wage growth is given by

$$
\left.\frac{\partial g}{\partial t}\right|_{\alpha=\alpha_{e}}=\left.\frac{\partial g}{\partial c}\right|_{\alpha=\alpha_{e}} \equiv g_{c}\left(c, \alpha_{e}\right)=g_{c}\left(t-\alpha_{e}, \alpha_{e}\right) \equiv e(t)
$$

again comprising two effects, namely a change of cohort and time.

Now, two testable separability conditions implying uniformity of wage trends can be introduced. If wage growth can be characterized as the sum of a pure aging effect and a pure time effect in the following way

$$
g_{\alpha}=a(\alpha)+b(t)=a(\alpha)+b(c+\alpha),
$$

then life-cycle wage growth is independent of the calendar year $t$. This condition is designated as the "uniform insider wage growth hypothesis" which we denote by $H_{U I}$. It implies that each cohort faces the same wage growth over the life-cycle due to aging $a(\alpha)$ and that economy wide shifts $b(t)$ are common to all cohorts in the same year but they occur at different points during the life-cycle of each cohort. If the separability condition (5) holds, we can construct a "life-cycle wage profile" independently of the calendar year and a macroeconomic time trend independently of age. Condition (5) is violated if interaction terms of $\alpha$ and $t$ enter the specification of $g_{\alpha}$.

Integrating back the derivative condition (5) with respect to $\alpha$ yields an additive form for the systematic component of the wage function $g(c, \alpha)$ :

$$
g(c, \alpha)=G+K(c)+A(\alpha)+B(c+\alpha)
$$

where $G+K(c)$ is the cohort specific constant of integration. At a given point in time, the wages of cohorts differ only by the age-effect, given by $A(\alpha)$, and by a cohortspecific level, given by $K(c)$. The "uniform insider wage growth hypothesis" $H_{U I}$ can be tested by investigating whether "interaction terms" $R(\alpha, t)$ enter specification (6) which are constructed as integrals of interaction terms of $\alpha$ and $t$ in $g_{\alpha}$.

If, in addition to uniform wage growth across cohorts, the growth of entry wages equals the macroeconomic wage growth

$$
e(t)=b(t)
$$

a stronger hypothesis can be formulated which we designate as the "uniform wage growth hypothesis" denoted as $H_{U}$. Under this hypothesis, the life-cycle profile of each new labor market cohort is a parallel shift of the profile of the previous cohort corresponding to the uniform time trend $b(t)$ for all cohorts already in the labor market. Again, this is a testable implication. Given specification (6), condition (7) implies that $K(c)$ is equal to zero for the cohorts entering the labor market during the period of observation. 


\subsection{Empirical Implementation}

In order to describe wage profiles and to test the implications of uniform insider and entry wage growth, we specify the wage function $g(c, \alpha)$ using a fairly flexible functional form, which nests the different hypotheses about uniform wage growth as special cases.

A general regression equation for the wage of individual $i$ in the sample year $t$ can be written as:

$$
\ln \left[w_{i, t}\right]=g\left(c_{i}, \alpha_{i, t}\right)+\bar{u}_{t}+u_{i, t}
$$

where $\alpha_{i, t}$ and $c_{i}$ denote the age of individual $i$ at time $t$ and the cohort of individual $i$, respectively. We further decompose the error term into a period specific fixed effect $\bar{u}_{t}$ and a stochastic error term $u_{i t}$. In the empirical analysis, we take the age of 25 years as the entry age into the labor market and we define $\alpha=($ age -25$) / 10$ and therefore $\alpha_{e}=0$. Analogously, since the observation period starts in 1975, we define time $t=($ calendar year -1975$) / 10$. For each cohort, $c$ corresponds to the time $t$ at which $\alpha$ equals zero. For the cohort of age 25 in the year $1975, c$ equals zero and older cohorts have negative values for $c$.

As a flexible empirical approximation of the wage profile imposing the hypothesis of uniform insider wage growth, we use polynomials in age, cohort, and time:

$$
\begin{aligned}
A(\alpha) & =A_{1} \alpha+A_{(2)}(\alpha)=A_{1} \alpha+A_{2} \alpha^{2}+A_{3} \alpha^{3} \\
B(t) & =B_{1} t+B_{(2)}(t)=B_{1} t+B_{2} t^{2}+B_{3} t^{3}+B_{4} t^{4}+B_{5} t^{5} \\
K(c) & =K_{1} c+(1-\delta) K_{b}(c)+\delta K_{a}(c) \\
\text { with } \delta & =1 \text { for } c \geq 0 \text { and } \delta=0 \text { else. }
\end{aligned}
$$

The choice of polynomials is justified since the analysis does not intend to forecast wages outside the observed sample. For older cohorts, entering before the sample period (i.e. before 1975), the cohort term takes the form $K(c)=K_{1} c+K_{b}(c)$ and for younger cohorts, entering during the sample period (i.e. after 1975), the cohort term is $K(c)=K_{1} c+K_{a}(c)$, where:

$$
K_{b}(c)=K_{b 2} c^{2}+K_{b 3} c^{3} \quad \text { and } \quad K_{a}(c)=K_{a 2} c^{2} .
$$

Since $c$ takes the value zero for cohorts of age 25 in $1975, K(c)$ is zero for this specific cohort and the cohort effects are centered around this cohort.

We include year dummies which are orthogonalized with respect to $B(t)$ in order to estimate period specific fixed effects $\bar{u}_{t}$. The specification of the estimated wage function is augmented by orthogonalized time dummies $\sum_{i=1975}^{1995-N_{b}-1} \kappa_{i} Y D_{i}$, where $N_{b}$ is the order of the time polynomial $B(t)$, and the $\kappa_{i}$ 's are the coefficients of the orthogonalized year dummies $Y D_{i}$. The time effects for the years $i=1995-N_{b}, \ldots, 1995$ are estimated implicitely by assuming that the sequence of estimated time effects $\kappa_{i}, i=1975, \ldots, 1995$ is uncorrelated with $B(t)=B_{1}+B_{2}(t)$ and therefore with each power of $t$ up to $N_{b}$. These $N_{b}+1$ restrictions are incorporated into the definition of the orthogonalized year dummies $Y D_{1975}, \ldots, Y D_{1995-N_{b}-1}$. The orthogonalization implies that $B(t)$ is estimated as if no cyclical effects were present in the regression. Thus, $B(t)$ can be interpreted as the trend component and the orthogonalized remaining time effects as 
the business cyclical component. In the empirical application, we choose a fifth order polynomial in time for $B(t)\left(N_{b}=5\right)$, which seems to yield a satisfactory decomposition of trend and cycle.

The hypothesis of uniform insider wage growth requires equation (6) to hold against a more general alternative, whereas the (stronger) uniform wage growth hypothesis additionally requires the coefficients of $K_{a}$ to be zero. Formally, it is also possible to test the hypothesis that the cohort effects $K_{b}$ are zero. But this test of equation (7) for older cohorts is not directly based on the entry wages of these cohorts. Instead, it relies on the implications of the hypothesis for the wage profile in later stages of the life-cycle.

In order to formulate a test of the hypothesis of uniform insider wage growth, we consider in the derivative $g_{\alpha}$ the following interaction terms of age and time:

$$
\alpha t, \alpha t^{2}, \alpha^{2} t, \alpha^{2} t^{2}
$$

The implied non-separable variant of $g(c, \alpha)$ expands $(6)$ by incorporating the integrals of (10) which are denoted by $R_{1}, \ldots, R_{4}$. For instance, $R_{1}$ is defined as follows:

$$
R_{1}=\int \alpha(c+\alpha) d \alpha=\left(c \alpha^{2} / 2\right)+\left(\alpha^{3} / 3\right)
$$

Consequently, the most general formulation of equation (8) becomes

$$
\begin{aligned}
g(c, \alpha)+\bar{u}_{t}= & G+\left(A_{1}-K_{1}\right) \alpha+\left(B_{1}+K_{1}\right) t+A_{(2)}(\alpha)+B_{(2)}(t) \\
& +(1-\delta) K_{b}(c)+\delta K_{a}(c)+\sum_{i=1}^{4} \gamma_{i} R_{i}+\sum_{i=1975}^{1995-N_{b}-1} \kappa_{i} Y D_{i}
\end{aligned}
$$

A formal test of the uniform insider wage growth hypothesis is:

$$
\mathbf{H}_{\mathbf{U I}}: \quad R_{1}, \ldots, R_{4} \text { do not appear in } g(c, \alpha)
$$

and the test of the stronger hypothesis of uniform wage growth is:

$$
\mathbf{H}_{\mathbf{U}}: \quad R_{1}, \ldots, R_{4} \quad \text { do not appear in } g(c, \alpha) \text { and } K_{a}=0
$$

Only if the separability condition $H_{U I}$ holds, is it meaningful to construct an index of a life-cycle wage profile as a function of pure aging and a macroeconomic trend index. Otherwise, a different wage profile would apply for each cohort. Thus, provided $H_{U I}$ holds, the life-cycle $(L)$ is given by

$$
\ln \left[w_{L}(\alpha)\right]=\left(A_{1}-K_{1}\right) \alpha+A_{(2)}(\alpha)
$$

and the macroeconomic $(m)$ wage trend index is given by

$$
\ln \left[w_{m}(t)\right]=\left(B_{1}+K_{1}\right) t+B_{(2)}(t) .
$$

When interpreting these indices, it is important to recognize that neither the level nor the coefficient on the linear term are identified in a strict econometric sense. In fact, identification relies on the assumption that the coefficient on the linear cohort term is equal to zero. This assumption is motivated by equation $(5)-$ provided it is 
justified in light of the data - which allows to decompose wage growth into a pure age and a pure time effect which are both common to all cohorts in the labor market. In light of this condition, setting the linear cohort term to zero is quite natural. If, for instance, also entry wages grow at the same rate as the time effect $b(t)$ before and during the sample period, the entire cross-section profile $f(\alpha, t)$ exhibits purely parallel shifts over time, a situation, one would not naturally characterize by "cohort effects". When uniform insider-wage growth is accepted, our notion of a cohort effect requires a situation where the differences in starting points of the common life-cycle profile differ from the macroeconomic wage growth experienced by the cohorts in the labor market.

\subsection{Quantile Regression Approach}

The literature typically investigates movements in mean log wages based on least squares (or tobit for the case of censoring) estimation procedures. This allows one to measure how the mean of the conditional wage distribution differs across workers with different socio-economic characteristics and how that mean changes over time. However, it is also of great interest to measure within-group differences and their movement over time. Another group of more descriptive studies, see among others OECD (1996), describes the time trends in quantile differences of wages for some broadly defined groups of workers (like full-time working males or females) in order to analyze trends in wage dispersion on a fairly aggregated level. However, it is rarely analyzed whether within-wage dispersion differs across workers with different characteristics.

Quantile regressions, developed by Koenker and Bassett (1978), provide a very useful tool to study wage differences across and within groups of workers with different socio-economic characteristics and how they evolve over time. In this respect, quantile regressions combine the two approaches outlined in the previous paragraph. In addition, quantile regressions exhibit certain robustness properties due to the insensitivity of empirical quantiles to outliers in wages and the fact that they can be extended to the censored case without losing their robustness properties, see Powell (1986). Since the data used in this study are topcoded, i.e. wages are censored from above, we now introduce the notation for censored quantile regressions.

For general $\theta \in(0,1)$, we estimate conditional quantiles of wages

$$
q_{\theta}\left(\ln \left[w_{i, t}\right] \mid c, \alpha, \beta^{\theta}\right)=g^{\theta}\left(c, \alpha, \beta^{\theta}\right)+\bar{u}_{t}^{\theta},
$$

where $q_{\theta, t}\left(\ln \left[w_{i, t}\right] \mid c, \alpha, \beta^{\theta}\right)$ denotes the $\theta$-quantile of the wage in cohort-age-cell $(c, \alpha)$ (三 cohort-year-cell $(c, t)$ where $t=c+\alpha)$. The vector $\beta^{\theta}$ comprises the coefficients in equation (12) relating to the set of regressors $x_{i, t}$ (三 powers of $c, \alpha$ and $t$; year dummies). In the empirical analysis, we model the following quantiles: $\theta=0.2,0.5,0.8$ $\left(20 \%^{-}, 50 \%-\right.$, and $80 \%-$ quantile).

We use a simplified minimum-distance approach suggested among others by Chamberlain $(1994)^{10}$ for the estimation of quantile regressions when the data on the regressors can be grouped into cells and censoring is not too severe. The approach consists of

\footnotetext{
${ }^{10}$ See Gosling et al. (1996), MaCurdy and Mroz (1995), Fitzenberger et al. (1995), and Fitzenberger (1999) for studies using this approach.
} 
calculating the respective cell quantiles in a first stage and regressing (by weighted least squares) those empirical quantiles, which are not censored, on the set of regressors in the second stage. For the dataset used in this study, the cell sizes are large enough for making this a fruitful approach (Chamberlain suggests cell sizes of at least 30). However, we do not estimate the $80 \%$-quantile for males in skill group (H) since censoring is too severe in this case. When applying the minimum-distance approach, we use the cell sizes as weights, but we do not attempt to weight the cells efficiently using an estimate of the variance of the empirical quantile. Available estimators of the variance within cells typically require an i.i.d. assumption within the cell, which wo do not find credible, and an estimate of the density at the quantile under investigation. The standard error estimates are robust with respect to the weighting procedure (see the next subsection).

\subsection{Block Bootstrap Procedure for Inference}

In the context of this study, we allow for the error terms being dependent across individuals within cohort-year-cells and across adjacent cohort-year-cells. The dependence is assumed to take the form of rectangular m-dependence across time and across cohorts. We use a flexible Block Bootstrap approach allowing for standard error estimates which are robust against fairly arbitrary heteroskedasticity and autocorrelation of the error term, see Fitzenberger and MaCurdy (1996). The Block Bootstrap approach employed here extends the standard bootstrap procedure in that it draws blocks of observations to form the resamples. For each observation in a block, the entire vector comprising the endogenous variable and the regressors is used, i.e., we do not draw from the estimated residuals. We draw a two-dimensional block of observations of block length eight in the cohort and six in the time dimension with replacement until the resample has become at least as large as the resample size. ${ }^{11}$ Accordingly, standard error estimation takes account of error correlation both within a cohort-year-cell and across pairs of cohorts and time periods which are at most seven years in the cohort dimension and five years in the time dimension apart.

For the weighted least squares estimation based on cell quantiles, we simply draw the blocks of at most 48 cohort-year-cells to form the resample. In addition to the cell quantile and the regressor vector, each cell also has a weight attached (number of workers) which is used in the weighted least squares regression on the resample. When the design matrix for a resample becomes rank deficient (this happens frequently with dummy specifications) the resample is dismissed. Contrasting the results presented in section 5 with conventional standard error estimates (the latter are not reported here) indicates that allowing for correlation between the error terms within and across cohort-year-cells (when forming the blocks) changes the estimated standard errors considerably. Thus, it is very likely that such correlation is present and important for inference. In the absence of a clear cut decision rule about the choice of blocksize, we experimented somewhat with slightly smaller or larger blocks without changes in the substance of the results.

\footnotetext{
${ }^{11}$ When resampling, we draw new blocks until the size of the resample is equal to or larger than the respective sample.
} 


\section{$5 \quad$ Empirical Results}

Based on the empirical framework introduced above, this section discusses the estimated specifications and then presents the empirical results.

\subsection{Estimated Specifications for Wage Equations}

Depending on the degree of uniformity in wage growth imposed, we estimate five specifications (model 1 to 5 ) of equation (12) for the $20 \%-, 50 \%-$, and $80 \%$-quantile for males, full-time working females, and part-time working females by skill groups (U), $(\mathrm{M})$, and $(\mathrm{H})$. The high degree of censoring allows only estimation for the $20 \%-$ and the $50 \%$-quantile in the case of high-skilled (H) males.

The estimation results of the preferred final specifications for the several subgroups can be found in tables 1-3 (for figures and tables see appendix). The standard error estimates are obtained by a block bootstrap procedure as described in section 4.6. We will postpone the discussion of the differences between the nine settings to the section describing the preferred specifications by means of graphical illustrations.

The most general specification (model 1) is given by

$$
\begin{aligned}
g(c, \alpha)= & G+a_{1} \alpha+a_{2} \alpha^{2}+a_{3} \alpha^{3}+b_{1} t+b_{2} t^{2}+b_{3} t^{3}+b_{4} t^{4}+b_{5} t^{5} \\
& +\gamma_{b 2} c_{b}^{2}+\gamma_{b 3} c_{b}^{3}+\gamma_{a 2} c_{a}^{2}+\sum_{j=1}^{4} \rho_{j} R_{j},
\end{aligned}
$$

where the age polynomial is of order 3 , the time polynomial of order 5 , and $c_{b}=(1-\delta) c$ and $c_{a}=\delta c$ are the cohort terms before and after 1975. All specifications include the cyclical year dummies $Y D_{i}$ which are orthogonalized with respect to the time trend. For part-timers we include the share of females working less than half full-time hours $(k l h)$ and its interactions with the linear terms of age $(k l h * a)$ and time $(k l h * t)$. Models 2 to 5 are restricted versions of model 1 :

Model 2: $\rho_{j}=0$ for $j=1, \ldots, 4$ ( $H_{U I}$ imposed $)$,

Model 3: $\rho_{j}=0$ for $j=1, \ldots, 4$, and $\gamma_{a 2}=0$ ( $H_{U}$ imposed $)$,

Model $4: \rho_{j}=0$ for $j=1, \ldots, 4$, and $\gamma_{a 2}=0\left(H_{U}\right.$ imposed $)$, and $\gamma_{b 2}=\gamma_{b 3}=0$, and

Model 5: $\rho_{j}=0$ for $j=1, \ldots, 4$, and $\gamma_{b 2}=\gamma_{b 3}=0$.

Models 2 to 5 impose separability of wage growth into age and time effects. Model 3 sets cohort effects after 1975, and model 5 cohort effects before 1975 to zero.

The most restricted version, model 4, assumes that wage growth is uniform across cohorts, both during and before the sample, i.e. there are no "cohort effects" for those cohorts entering the labor market before the start of the sample in 1975. Under this scenario, wage growth can be described by a fixed cross-section age profile of wages 
which moves in parallel fashion over time. Thus, the cross-section age profile corresponds to the true life-cycle profile experienced by each cohort. In this situation, we do not consider cohort effects to be operating, which motivates the identifying assumption that the linear cohort effect in models 1 to 5 is arbitrarily set to zero and therefore can be completely ascribed to the age and time profiles. However, while for males model 4 is typically not justified by the data this is - to our great surprise - always the case for females.

In contrast, model 3 restricts wage growth to be uniform across all cohorts only during the sample period. Wages of new cohorts entering the labor market grow at the same rate as wages for older cohorts apart from life-cycle effects. Nevertheless, it is possible that cross-section age profiles of wages change over time due to "cohort effects" before the start of the sample. Model 2 allows "cohort effects" to operate both for the cohorts entering the labor market before and during the sample period. However, it still restricts wage growth to be uniform across cohorts after having entered the labor market.

Model 5 allows cohort effects to occur only for workers who entered the labor market during the observed time span. In this model, entry wages after 1975 do not grow according to the estimated time trend, that means only younger cohorts experience cohort effects.

To test the wage growth hypotheses $H_{U I}$ and $H_{U}$ we carry out a sequence of Wald tests. Starting from model 1, we test consecutively whether models 2 to 5 provide a sufficient description of the data. These test results determine the preferred models which are reported in tables 1-3 and which the illustrations of wage profiles in the following subsection are based upon. Analogously building on the preferred specifications, we calculate several tests investigating uniformity of the preferred coefficient estimates across quantiles (available upon request).

Turning to the results for the uniform wage growth hypotheses $\left(H_{U I}\right.$ and $\left.H_{U}\right)$, i.e. testing the restrictions implied by models 2, 3, 4 (and 5 for high-skilled males) we find that in general model 1 is always rejected by the data. Consequently, we take separability of age and time effects in all cases as given. In the following, it is therefore possible to construct life-cycle wage profiles and macroeconomic time trends for all groups considered.

For men of skill group (U), model 3 is appropriate with cohort effects operating during the sample period for those who have entered the labor market be fore the sample period. Men of skill group (M) fit better in model 2. So (M)-workers who started working before and during the sample period experience cohort effects during the observed time span. Men of skill group (H) are best represented by model 5 (whith a quadratic cohort-term for younger males and the cohort-terms for older men dropped). This means that alike men of the medium-skill group there are cohort effects during the sample period at work for the younger men who have entered the labor market during this time. The aforementioned models apply to all estimated quantiles within the respective cells of skill groups (for high-skilled males only $20 \%$ - and $50 \%$-quantiles). That means, as far as males are concerned, cohort effects - which lead to parallel shifts of the life-cycle earnings profile over time - do exist, and entry wages of younger 
medium- and high-skilled males who started working during the observation period do not simply differ across cohorts by the estimated time trends.

Unexpectedly the opposite is true for full-time and part-time employed females for whom we do not find any cohort effects. ${ }^{12}$ In this case model 4 is the preferred model and applies to all quantiles. It is especially surprising that for women, in particular for women who started working during the observed 21 years, cohort effects are nonexistent. In our empirical framework the skill upgrading of females starting in the sixties and seventies seems to have no impact per se on female wages. Put differently, it is possible that composition and selection effects interfere, which we have not controlled for yet. Composition- and selection effects are likely in the case of females, because their employment patterns and labor market attachment has changed very much during the last three decades. Because we interpret the finding of cohort effects for the younger medium- and high-skilled men entering the labor market after 1975 as effects of skill upgrading in a basically stable male employment setting, it is obviously necessary to control for composition and selection effects of changes in female employment in further research from a labor demand perspective. It could also be the case that women of the same skill level but different ages are much closer substitutes compared to males. In the case of perfect substitutability it is plausible to find no cohort effects.

To complete the results on model specification, we have tested whether the quantile regression estimates differ significantly by quantiles. We mostly find significant differences even though these differences are often not economically meaningful. Instead of providing many test statistics (these test results are available on request), we choose to present this aspect by means of graphical illustrations of our preferred estimated models accross quantiles in the next subsection. This way, we can directly emphasize the economically important differences.

\subsection{Graphical Illustrations}

In the following, we present graphical illustrations of the preferred estimated models corresponding to the test results presented in the previous subsection. These graphical illustrations (see appendix) prove convenient to describe the findings of this paper. First, since uniform insider wage growth $\left(H_{U I}\right)$ is accepted for all specifications, it is meaningful to construct profiles of life-cycle wage growth and time trends. Then, we analyze male-female wage differentials in estimated time trends in order to investigate to what extent full-time and part-time working women were able to improve their wage positions compared to men.

\section{Life-Cycle Profiles}

Figures 5 and 6 depict the predicted life-cycle profiles for males and for full-time and part-time working females. The graphs show men compared to full-time- and men

\footnotetext{
${ }^{12}$ Computation with pooled data for part-time and full-time females exhibited significant cohort effects. In contrast, visual inspection of fitted cross section profiles contradicted cohort effects because life-cycle profiles for given cells were quite constant over time.
} 
compared to part-time working women. The graphs for older high-skilled men at the $50 \%$-quantile and older high-skilled full-time women at the $80 \%$-quantile should not be taken too seriously because cells are censored in these cases. Therefore the predicted profiles for higher ages are to be viewed as out-of-sample predictions.

Comparing low-skilled (U) men and women it becomes apparent that the life-cycle profiles of full-time working women are much flatter and even negative in the lower part of the wage distribution. For low-skilled men, the distribution does not change very much over the life-cycle. At all quantiles, wage growth is nearly identical with the lowest quantile a little ahead which points to a compression of the within cell distribution. Low-skilled full-time women experience in general very little growth of under $10 \%$ over their life-cycle. The lowest quantile ends at 55 years where it started at the age of 25 being negative in between. The within cell distribution of low-skilled female full-timers enlarges to a difference of only $10 \%$ between the $20 \%$ - and the $80 \%$-quantile at the end of the life-cycle. In contrast, the within cell distribution of low-skilled part-timers becomes more compressed over the life-cycle. The profile of the $80 \%$-quantile is stable over time at $0 \%$, the $50 \%$-quantile grows by $5 \%$ and the $20 \%$ quantile by $10 \%$ until the age of 55 years. Put together, for male and female low-skilled workers wage inequality is nearly stable over the life-cycle. It increases very little in the case of full-time women and decreases both for males and part-time females. The wage growth is in general relatively weak with a maximum of nearly $20 \%$ for the $20 \%$-quantile of males and female part-timers.

The picture changes when we look at medium-skilled (M) workers. The life-cycle wage growth of men is much higher than for women and reaches $32 \%, 45 \%$, and $60 \%$ $(20 \%-, 50 \%-$, and $80 \%$-quantile) implying a rather strong rise in within-cell inequality of wages over the life-cycle. A similar rise of inequality is observable for female fulltimers due to a surprisingly strong downward movement of the $20 \%$-quantile in this case, summing up to around $20 \%$ at the age of 55 . The median gains around $10 \%$ and the upper quantile $20 \%$ which is in both cases one third of male gains. Parttimers profiles are the flattest (a finding which is quite plausible taking into account the presumably lower rate of human capital accumulation of part-timers) with only marginal differences between the $80 \%$-quantile and the median. Both reach $10 \%$ at the end of their working life. Noteworthy is again the comparatively strong growth of $20 \%$ in the lower part of the distribution which leads to decreasing inequality of wages in this cell similar to what we found already for low-skilled female part-timers. The opposite is observable in the case of medium-skilled males and full-time working medium-skilled females. In both cases, we find a difference between the $20 \%$ - and the $50 \%$-quantile of around $30 \%$ at the age of 55 years. Very surprising are the losses of $20 \%$ faced by the $20 \%$-quantile of full-time women. The difference in wage growth over the life-cycle between the $20 \%$-quantiles of full-time working men and women then sums up to $50 \%$ at the age of 55 .

The finding of losses over the life-cycle in the case of medium- as well as low-skilled female full-timers at the $20 \%$-quantile contrasts sharply to the $20 \%$-quantile of parttime women (for low as well as medium skill level), for whom we observe the highest (but small) gains within the respective cells. Most likely this result reflects selection and composition effects. First, interrupting employment for individual reasons is certainly "cheaper" for females in the lower part of the wage distribution in terms of lost 
earnings. Second those women may be threatened disproportionately by unemployment because of comparatively high wages in this part of the skill distribution. Third, it is possible that employers are more likely to dismiss low-skilled married females with low wages than other employees. All together, this could lead to a higher probability of interruptions for those females and therefore to a severe depreciation or loss of human capital that can not be catched up again. On the one hand, part-timers, who accumulate less human capital of this kind, may have a more stable work career than full-time employed females in the lower part of the wage distribution. On the other hand, women working full-time when they are young might switch disproportionately to part-time employment when they are older. As a composition effect, this enhances the human capital endowment of part-time women at a higher age. If no such additional effects where operating, then the observed losses in the lower part of the wage distribution would have to be interpreted generally as decreasing returns to experience or that experience depreciates more quickly than it is built up in the case of lowand especially medium-skilled full-time working women. Considering the reasons why the profile at the $20 \%$-quantile looks so badly, one may suspect in addition that the unobserved quality of the group suffers over the life-cycle.

Now turning to high-skilled (H) women (part-timers and full-timers) and men, we find that women always exhibit a positive growth which ends at 55 years at around $20 \%$ for the $20 \%$-quantile, at around $30 \%$ for the $80 \%$-quantile, and $40 \%$ respectively $50 \%$ (for part-timers) for the median. This implies decreasing within cell wage inequality between median and 80\%-quantile. For high-skilled part-timers, the wage distribution is most unequal in the middle of the life-cycle and becomes more equal again after an age of 40 years. As far as men are concerned, it becomes obvious that the estimation of the $50 \%$-quantile can not be interpreted after age 35 . The reason for this somewhat peculiar course of the $50 \%$-quantile is the fact that almost all medians above the age 35 are censored. At the $20 \%$-quantile, we observe a strong growth of $55 \%$ which is even stronger than the growth of the most successful parts of both female wage distributions in skill group $(\mathrm{H})$.

All together we conclude: Life-cycle wage growth of women is always lower compared to males of comparable skill level. We also find that life-cycle wage growth differs substantially between female full- and part-timers of skill groups (U) and (M) leading to different movements of within cell distributions. While the $20 \%$-quantile of low and medium-skilled full-timers exhibits negative growth, the $20 \%$-quantile of part-timers grows strongest within the respective cells with the former leading to increasing, and the latter to decreasing within cell inequality. The increase in inequality in the case of medium-skilled full-timers is even stronger than for medium-skilled males.

\section{Time Trends}

Figures 7 and 8 depict the estimated time trends without cyclical effects based on the preferred final specifications. Based upon the acceptance of the uniform wage growth hypothesis, these time trends summarize the shifts in the wage distribution within and between the sill groups over time and entry wage growth in settings for which $K_{a}=0$ is accepted. The latter is always the case except for medium- and high-skilled males (see tables 1-3 appendix). The estimated time trends are used to show graphically the 
changes in male-female wage differences for given characteristics of the employees over the time period from 1975 to 1995 .

A first glance at the figures reinforces the impression we got already from the unconditional wage distributions. Men and women experience rather different wage trends over time and there are further differences between full-time and part-time working females as well as across skill groups. With the exception of high-skilled part-timers, women of all skill groups at all quantiles experience a stronger wage growth than their male counterparts.

Males in skill-group (U) show a more unequal trend in wages since the middle of the 1980 's resulting in a gap of $10 \%$ in the year 1995 . The lower part of the distribution ends up at $10 \%$, the upper part at $20 \%$, and the median somewhere in between. The time trends are quite different for low-skilled female full- and part-timers. Their endpoints are nearly $10 \%$ higher, and for full-timers the distribution becomes more compressed over time. Since about 1985 part-timers experience a widening at the upper end and a compression at the lower end of the distribution. Full- as well as part-time working women make on average nearly the same gains until 1995 but have clearly a stronger wage growth than males.

Skill-group (M): The macro trend of men does not involve a lot of change in inequality since all quantiles move in more or less the same way. The opposite occurs in the case of full-time females. Here we detect a catching up of the lower part of the distribution, resulting all together in a $35 \%$ wage growth until 1995 . In the upper part a widening of $2-3 \%$ is visible over time ending at $23 \%$ and $25 \%$ for the $50 \%-$ and $80 \%$-quantiles in 1995, respectively. Part-time working females experience neither widening nor shrinking of wage inequality between the median and the $80 \%$-quantile wheras the distance to the $20 \%$-quantile grows. Since the beginning of the 1980 's, the within cell wage distribution becomes more unequal. Despite this development, part-timers exhibit a steeper time-trend than males and a slower growth than full-time females.

Turning now to the high-skilled $(\mathrm{H})$ males and females, results are again limited by censoring. What we can conclude is that inequality of within-wages grows between the $20 \%$ - and 50\%-quantile for men and stays constant in the case of full-time women. The gains (around 15\%) are similar for the male median and all quantiles of female fulltimers. Part-time women of skill-group (H) exibit a very unusual time trend involving compression of wages from the lower part of the distribution and losses at the median and in the upper part of the distribution. Because high-skilled female part-timers are a comparatively small group, interpreting their time trends is difficult. Individual reasons for high-skilled females to be part-time employed (leaving aside child rearing), are hard to find in a context of human capital arguments. Possibly they can afford working part-time because of their higher income or possibly they choose to work in specific sectors like education (or the public sector in general), where part-time jobs are more easily to get.

Another look at figures 5 and 7 as well as 6 and 8 (right hand sides) contrasting female life-cycle profiles and their time trends uncovers some interesting facts. While life-cycle growth of low and medium-skilled full-timers is lowest in the lower part ( $20 \%$ ) of the within cell wage distributions, it proves to be highest over time for those 
females. Quite the opposite is observable for low-skilled and medium-skilled parttimers. While the 20\%-quantile exhibits the lowest (or low in comparison to other quantiles of the respective cells) growth over time, it gains most over the life-cycle.

Finally, we would like to summarize graphically the improvement of female wages compared to male wages by comparing the time trends of males and females of the same age and skill group. For this purpose, we have calculated relative differences of male and female time trends which we have studied separately so far. Full-time working females of skill group $(\mathrm{H})$ are compared to males of skill group (M) because of the severity of censoring for high-skilled males. Furthermore we do not discuss female part-timers of skill group $(\mathrm{H})$ because of the irregular trends in this case.

All graphs (see figure 9) show basically the same pattern, namely a general improvement of the female wage position which amounts to at least 10 , and to at most $27 \%$. Another impressive result which we have already discussed regarding the unconditional distributions and life-cycle profiles is that the largest gains are mostly to be found at the 20\%-quantiles. In particular, this is true for low-skilled part-timers (19\%) and full-timers $(22 \%)$ and for medium-skilled full-timers (27\%). Medium-skilled parttimers in the lower part (20\%-quantile) of the distribution, despite the larger gains at the other quantiles within that cell, catch up by $14 \%$. The trends at the other quantiles by skill levels are rather complex. At the median, medium-skilled part-timers are most successful. Here, median growth is stronger than the growth at the other two quantiles. High-skilled full-timers in comparison to medium-skilled males are the least successful of all females. Their catching up amounts to "only" $10 \%$ at average and varies only slightly over the different parts of the wage distribution. As part of future research, it has to be investigated from a labor demand perspective whether the wage gains in the lower part of the wage distribution were associated with disproportionate job losses in this segment of the labor market (see Hunt, 1997 for such an interpretation in the case of East Germany).

\section{Conclusions}

Our goal is to provide a comprehensive descriptive analysis of the level and the dynamics of the gender wage gap between 1975 and 1995 in West Germany, across the entire wage distribution, taking into account life-cycle and birth cohort effects. We prefer to investigate the entire distributions of males and females because of the shortcomings of conventional decomposition techniques which only "explain" differences in mean wages and therefore overlook the important changes in the other parts of the distribution. A decomposition of mean wage differences may lead to wrong interpretations since distributional and compositional effects can possibly be confounded. Therefore, we use quantile regressions to separate the different effects and trends for different quantiles of the wage distribution, skill levels, cohorts, and employment status.

In this paper we mainly adressed the question how wages differ between male and female workers and between different skill groups over the life-cycle and over time. Life-cycle wage growth of women is always lower compared to males of comparable formal skill level. Life-cycle growth for part-timers is in general lower than growth for 
full-time employed females. This finding fits perfectly the conventional human capital perspective. Nevertheless, as an exception, life-cycle wage growth differs substantially between low-skilled and medium-skilled female workers in full-time and part-time jobs leading to different trends of within cell distributions of wages. While the $20 \%$-quantile of low and medium-skilled full-timers exhibits negative growth, the $20 \%$-quantile of part-timers grows strongest.

The finding of negative life-cycle growth at the lowest quantiles of medium- and lowskilled full-time employed females may in general be attributed to different work careers of those females compared to females in the other parts of the distribution and to parttime employed females. But there are several other conceivable reasons for this finding, for example a higher risk of unemployment or a changing within cell distribution of unobservable ability due to skill upgrading. A higher risk of unemployment would lead to less human capital investment and stronger depreciation of human capital.

If orientations of women have changed towards a higher labor force participation and higher formal skill levels, one should observe a narrowing gender wage gap, e.g. due to stronger human capital investment. Such changes are likely to have a stronger effect on regular full-time jobs compared to part-time jobs. In addition, birth cohort effects on female wages could exist such that younger cohorts benefit disportionately from a reduction of the gender wage gap since younger cohorts have better chances to obtain higher formal skill levels and are more work-oriented. Surprisingly and in contrast to the hypothesis just stated, we do not find any cohort effects for female workers. What does that mean? Did skill upgrading really have no effects at all on life-cycle profiles of female wages? The following processes are difficult to separate: (1) In 1995 labor force participation of females is much higher than 21 years ago. But (2) where did participation rise? It is often stressed for Germany that the increase in participation pimarily included part-time jobs and that the overall volume (in hours) did not change very much. Furthermore: (3) How have females changed their labor supply over the life-cycle (decision for children?) with which consequences for their wages? (4) Human capital investment in formal education as well as in labor market experience has changed, but is it also adequately rewarded? How did the rewards change if they did so? (5) Skill upgrading of the younger cohorts leads to changes of within cell distribution of ability. More able females move into higher skill levels where they exert a downward shift of within ability. Within ability for low-skilled exhibits also a downward shift over time. Are average human capital rewards within the respective cells affected? (6) Has the risk of becoming unemployed and loosing human capital changed because of lower average productivity? At the same time one has to take into account that (7) the average ability of participating females has changed also, if the formerly participating females have been a special subsample with high ability and motivation. From stating these issues it should have become clear, what are the topics of further research and that potential selection and composition effects have to be controlled for.

As far as time trends are concerned, we find that men and women experience rather different wage trends over time and there are further differences between full-time and part-time working females as well as skill groups. With the exception of high-skilled part-timers, women of all skill groups and at all quantiles experience a stronger wage growth than their male counterparts. This translates into a narrowing gender wage gap 
over time. Women in part-time jobs experience a reduction in the gender wage gap to the same extent as women in full-time jobs. The least successful are high-skilled fulltime employed women and the most successful are low-skilled and medium-skilled fulland part-time working females especially at the $20 \%$-quantile. Because part-timers and full-timers have catched up to more or less the same amount, social efforts (e.g. union policies) to improve the relative earnings of women seem to have resulted in an improvement of the relative wage position of female workers both in regular full-time jobs and part-time jobs, even though the latter are less institutionally regulated. 


\section{Appendix}

Table 1: Parameter Estimates of Wage Specifications for Skill Group (U) - Males $M$, Full-Time $F(F)$ and Part-Time $F(P)$ Working Females (Standard Errors in Parentheses - Preferred Final Specification Only)

\begin{tabular}{|c|c|c|c|c|c|c|c|c|c|}
\hline Skill Group & \multicolumn{9}{|c|}{ (U) Low-Skilled } \\
\hline Quantile & \multicolumn{3}{|c|}{$\theta=0.2$} & \multicolumn{3}{|c|}{$\theta=0.5$} & \multicolumn{3}{|c|}{$\theta=0.8$} \\
\hline Group & $M$ & $F(F)$ & $F(P)$ & $M$ & $F(F)$ & $F(P)$ & $M$ & $F(F)$ & $\overline{F(P)}$ \\
\hline Specification & $(3)$ & (4) & $\overline{(4)}$ & $\overline{(3)}$ & (4) & $\overline{(4)}$ & $\overline{(3)}$ & $\overline{(4)}$ & $\overline{(4)}$ \\
\hline Intercept & $\begin{array}{c}4.349 \\
(.008)\end{array}$ & $\begin{array}{c}3.996 \\
(.032)\end{array}$ & $\begin{array}{c}3.542 \\
(.052)\end{array}$ & $\begin{array}{c}4.526 \\
(.008)\end{array}$ & $\begin{array}{c}4.274 \\
(.019)\end{array}$ & $\begin{array}{c}3.830 \\
(.048)\end{array}$ & $\begin{array}{c}4.687 \\
(.007)\end{array}$ & $\begin{array}{c}4.472 \\
(.023)\end{array}$ & $\begin{array}{r}4.103 \\
(.042)\end{array}$ \\
\hline$\alpha$ & $\begin{array}{c}.178 \\
(.016)\end{array}$ & $\begin{array}{c}-.106 \\
(.044)\end{array}$ & $\begin{array}{c}.167 \\
(.038)\end{array}$ & $\begin{array}{c}.164 \\
(.010)\end{array}$ & $\begin{array}{c}.049 \\
(.030)\end{array}$ & $\begin{array}{c}.101 \\
(.029)\end{array}$ & $\begin{array}{c}.174 \\
(.010)\end{array}$ & $\begin{array}{c}.110 \\
(.027)\end{array}$ & $\begin{array}{c}.028 \\
(.033)\end{array}$ \\
\hline$\alpha^{2}$ & $\begin{array}{c}-.043 \\
(.012)\end{array}$ & $\begin{array}{c}.051 \\
(.031)\end{array}$ & $\begin{array}{c}-.063 \\
(.028)\end{array}$ & $\begin{array}{l}-.050 \\
(.008)\end{array}$ & $\begin{array}{l}-.026 \\
(.019)\end{array}$ & $\begin{array}{l}-.046 \\
(.018)\end{array}$ & $\begin{array}{c}-.055 \\
(.008)\end{array}$ & $\begin{array}{c}-.064 \\
(.019)\end{array}$ & $\begin{array}{l}-.015 \\
(.021)\end{array}$ \\
\hline$\alpha^{3}$ & $\begin{array}{c}.005 \\
(.002)\end{array}$ & $\begin{array}{c}-.005 \\
(.006)\end{array}$ & $\begin{array}{c}.008 \\
(.005)\end{array}$ & $\begin{array}{c}.006 \\
(.001)\end{array}$ & $\begin{array}{c}.005 \\
(.003)\end{array}$ & $\begin{array}{c}.007 \\
(.003)\end{array}$ & $\begin{array}{c}.007 \\
(.001)\end{array}$ & $\begin{array}{c}.012 \\
(.004)\end{array}$ & $\begin{array}{c}.002 \\
(.004)\end{array}$ \\
\hline$t$ & $\begin{array}{c}.527 \\
(.045)\end{array}$ & $\begin{array}{c}.866 \\
(.163)\end{array}$ & $\begin{array}{c}.621 \\
(.162)\end{array}$ & $\begin{array}{l}.710 \\
(.036)\end{array}$ & $\begin{array}{l}.736 \\
(.071)\end{array}$ & $\begin{array}{c}.534 \\
(.091)\end{array}$ & $\begin{array}{c}.789 \\
(.036)\end{array}$ & $\begin{array}{c}.709 \\
(.120)\end{array}$ & $\begin{array}{c}.525 \\
(.119)\end{array}$ \\
\hline$t^{2}$ & $\begin{array}{r}-1.186 \\
(.152)\end{array}$ & $\begin{array}{r}-1.935 \\
(.445)\end{array}$ & $\begin{array}{r}-1.593 \\
(.396)\end{array}$ & $\begin{array}{l}-1.867 \\
(.104)\end{array}$ & $\begin{array}{l}-1.661 \\
(.231)\end{array}$ & $\begin{array}{l}-1.424 \\
(.233)\end{array}$ & $\begin{array}{l}-2.213 \\
(.110)\end{array}$ & $\begin{array}{r}-1.680 \\
(.307)\end{array}$ & $\begin{array}{r}-1.390 \\
(.302)\end{array}$ \\
\hline$t^{3}$ & $\begin{array}{c}1.156 \\
(.199)\end{array}$ & $\begin{array}{r}2.116 \\
(.559)\end{array}$ & $\begin{array}{c}1.732 \\
(.487)\end{array}$ & $\begin{array}{c}2.061 \\
(.134)\end{array}$ & $\begin{array}{l}1.748 \\
(.314)\end{array}$ & $\begin{array}{l}1.587 \\
(.287)\end{array}$ & $\begin{array}{c}2.546 \\
(.145)\end{array}$ & $\begin{array}{r}1.782 \\
(.359)\end{array}$ & $\begin{array}{l}1.589 \\
(.368)\end{array}$ \\
\hline$t^{4}$ & $\begin{array}{c}-.463 \\
(.112)\end{array}$ & $\begin{array}{r}-1.008 \\
(.315)\end{array}$ & $\begin{array}{c}-.755 \\
(.264)\end{array}$ & $\begin{array}{l}-.945 \\
(.074)\end{array}$ & $\begin{array}{l}-.774 \\
(.181)\end{array}$ & $\begin{array}{l}-.690 \\
(.155)\end{array}$ & $\begin{array}{r}-1.207 \\
(.083)\end{array}$ & $\begin{array}{c}-.783 \\
(.189)\end{array}$ & $\begin{array}{c}-.690 \\
(.200)\end{array}$ \\
\hline$t^{5}$ & $\begin{array}{c}.061 \\
(.022)\end{array}$ & $\begin{array}{c}.173 \\
(.064)\end{array}$ & $\begin{array}{c}.113 \\
(.052)\end{array}$ & $\begin{array}{l}.151 \\
(.014)\end{array}$ & $\begin{array}{l}.120 \\
(.037)\end{array}$ & $\begin{array}{c}.101 \\
(.030)\end{array}$ & $\begin{array}{c}.200 \\
(.017)\end{array}$ & $\begin{array}{c}.120 \\
(.036)\end{array}$ & $\begin{array}{c}.099 \\
(.039)\end{array}$ \\
\hline$c_{b}^{2}$ & $\begin{array}{c}-.058 \\
(.009)\end{array}$ & - & - & $\begin{array}{l}-.041 \\
(.008)\end{array}$ & - & - & $\begin{array}{c}-.047 \\
(.006)\end{array}$ & - & - \\
\hline$c_{b}^{3}$ & $\begin{array}{c}-.011 \\
(.003)\end{array}$ & - & - & $\begin{array}{c}-.009 \\
(.003)\end{array}$ & - & - & $\begin{array}{c}-.011 \\
(.002)\end{array}$ & - & - \\
\hline$c_{a}^{2}$ & - & - & - & - & - & - & - & - & - \\
\hline klh & - & - & $\begin{array}{c}-.008 \\
(.001)\end{array}$ & - & - & $\begin{array}{l}-.004 \\
(.002)\end{array}$ & - & - & $\begin{array}{l}-.002 \\
(.002)\end{array}$ \\
\hline$k l h * t$ & - & - & $\begin{array}{c}-.003 \\
(.002)\end{array}$ & - & - & $\begin{array}{l}-.001 \\
(.001)\end{array}$ & - & - & $\begin{array}{c}-.002 \\
(.001)\end{array}$ \\
\hline$k l h * a$ & - & - & $\begin{array}{c}-.000 \\
(.000)\end{array}$ & - & - & $\begin{array}{l}.000 \\
(.000)\end{array}$ & - & - & $\begin{array}{c}.001 \\
(.001)\end{array}$ \\
\hline
\end{tabular}

a: The estimate of the covariance matrix is obtained using a Block Bootstrap Procedure (1000 resamples for skill groups (U) and $(\mathrm{M})$ and $(\mathrm{H})$ ). The blocks allow for dependence across six adjacent time periods and across eight adjacent cohorts. 
Table 2: Parameter Estimates of Wage Specifications for Skill Group (M) - Males $M$, Full-Time $F(F)$ and Part-Time $F(P)$ Working Females (Standard Errors in Parentheses - Preferred Final Specification Only)

\begin{tabular}{|c|c|c|c|c|c|c|c|c|c|}
\hline Skill Group & \multicolumn{9}{|c|}{ (M) Medium-Skilled } \\
\hline Quantile & \multicolumn{3}{|c|}{$\theta=0.2$} & \multicolumn{3}{|c|}{$\theta=0.5$} & \multicolumn{3}{|c|}{$\theta=0.8$} \\
\hline Group & $M$ & $F(F)$ & $F(P)$ & $M$ & $F(F)$ & $F(P)$ & $M$ & $F(F)$ & $F(P)$ \\
\hline Specification & $\overline{(2)}$ & (4) & (4) & $\overline{(2)}$ & (4) & (4) & $(2)$ & (4) & (4) \\
\hline Intercept & $\begin{array}{c}4.457 \\
(.008)\end{array}$ & $\begin{array}{c}4.179 \\
(.041)\end{array}$ & $\begin{array}{c}3.726 \\
(.071)\end{array}$ & $\begin{array}{c}4.620 \\
(.006)\end{array}$ & $\begin{array}{c}4.460 \\
(.031)\end{array}$ & $\begin{array}{c}3.925 \\
(.036)\end{array}$ & $\begin{array}{c}4.762 \\
(.015)\end{array}$ & $\begin{array}{c}4.606 \\
(.022)\end{array}$ & $\begin{array}{r}4.237 \\
(.043)\end{array}$ \\
\hline$\alpha$ & $\begin{array}{c}.267 \\
(.014)\end{array}$ & $\begin{array}{c}-.260 \\
(.067)\end{array}$ & $\begin{array}{c}.134 \\
(.038)\end{array}$ & $\begin{array}{c}.325 \\
(.013)\end{array}$ & $\begin{array}{c}.166 \\
(.038)\end{array}$ & $\begin{array}{l}.120 \\
(.018)\end{array}$ & $\begin{array}{c}.410 \\
(.022)\end{array}$ & $\begin{array}{c}.304 \\
(.031)\end{array}$ & $\begin{array}{c}.068 \\
(.034)\end{array}$ \\
\hline$\alpha^{2}$ & $\begin{array}{c}-.099 \\
(.009)\end{array}$ & $\begin{array}{c}.084 \\
(.056)\end{array}$ & $\begin{array}{c}-.025 \\
(.027)\end{array}$ & $\begin{array}{c}-.105 \\
(.008)\end{array}$ & $\begin{array}{c}-.116 \\
(.029)\end{array}$ & $\begin{array}{c}-.039 \\
(.013)\end{array}$ & $\begin{array}{c}-.115 \\
(.015)\end{array}$ & $\begin{array}{c}-.153 \\
(.024)\end{array}$ & $\begin{array}{c}.001 \\
(.021)\end{array}$ \\
\hline$\alpha^{3}$ & $\begin{array}{c}.015 \\
(.002)\end{array}$ & $\begin{array}{c}-.005 \\
(.013)\end{array}$ & $\begin{array}{c}.001 \\
(.005)\end{array}$ & $\begin{array}{c}.015 \\
(.001)\end{array}$ & $\begin{array}{c}.024 \\
(.006)\end{array}$ & $\begin{array}{c}.004 \\
(.002)\end{array}$ & $\begin{array}{c}.015 \\
(.003)\end{array}$ & $\begin{array}{c}.025 \\
(.005)\end{array}$ & $\begin{array}{l}-.004 \\
(.004)\end{array}$ \\
\hline$t$ & $\begin{array}{c}.380 \\
(.030)\end{array}$ & $\begin{array}{c}.627 \\
(.209)\end{array}$ & $\begin{array}{c}.510 \\
(.148)\end{array}$ & $\begin{array}{c}.507 \\
(.026)\end{array}$ & $\begin{array}{c}.510 \\
(.155)\end{array}$ & $\begin{array}{l}.494 \\
(.093)\end{array}$ & $\begin{array}{c}.711 \\
(.074)\end{array}$ & $\begin{array}{c}.558 \\
(.099)\end{array}$ & $\begin{array}{c}.549 \\
(.110)\end{array}$ \\
\hline$t^{2}$ & $\begin{array}{c}-.779 \\
(.092)\end{array}$ & $\begin{array}{l}-1.504 \\
(.595)\end{array}$ & $\begin{array}{l}-1.370 \\
(.400)\end{array}$ & $\begin{array}{l}-1.366 \\
(.086)\end{array}$ & $\begin{array}{l}-1.249 \\
(.417)\end{array}$ & $\begin{array}{l}-1.352 \\
(.202)\end{array}$ & $\begin{array}{l}-2.110 \\
(.199)\end{array}$ & $\begin{array}{r}-1.338 \\
(.271)\end{array}$ & $\begin{array}{l}-1.612 \\
(.302)\end{array}$ \\
\hline$t^{3}$ & $\begin{array}{c}.590 \\
(.122)\end{array}$ & $\begin{array}{c}1.734 \\
(.743)\end{array}$ & $\begin{array}{c}1.467 \\
(.488)\end{array}$ & $\begin{array}{c}1.356 \\
(.117)\end{array}$ & $\begin{array}{c}1.336 \\
(.503)\end{array}$ & $\begin{array}{l}1.515 \\
(.245)\end{array}$ & $\begin{array}{c}2.402 \\
(.250)\end{array}$ & $\begin{array}{c}1.404 \\
(.339)\end{array}$ & $\begin{array}{r}1.849 \\
(.381)\end{array}$ \\
\hline$t^{4}$ & $\begin{array}{c}-.134 \\
(.069)\end{array}$ & $\begin{array}{c}-.832 \\
(.403)\end{array}$ & $\begin{array}{c}-.634 \\
(.256)\end{array}$ & $\begin{array}{c}-.533 \\
(.067)\end{array}$ & $\begin{array}{c}-.582 \\
(.268)\end{array}$ & $\begin{array}{l}-.669 \\
(.134)\end{array}$ & $\begin{array}{r}-1.128 \\
(.141)\end{array}$ & $\begin{array}{c}-.588 \\
(.187)\end{array}$ & $\begin{array}{l}-.835 \\
(.205)\end{array}$ \\
\hline$t^{5}$ & $\begin{array}{c}-.004 \\
(.014)\end{array}$ & $\begin{array}{c}.142 \\
(.078)\end{array}$ & $\begin{array}{c}.096 \\
(.048)\end{array}$ & $\begin{array}{c}.068 \\
(.013)\end{array}$ & $\begin{array}{c}.088 \\
(.051)\end{array}$ & $\begin{array}{l}.102 \\
(.026)\end{array}$ & $\begin{array}{c}.186 \\
(.029)\end{array}$ & $\begin{array}{c}.083 \\
(.037)\end{array}$ & $\begin{array}{c}.130 \\
(.039)\end{array}$ \\
\hline$c_{b}^{2}$ & $\begin{array}{c}-.053 \\
(.007)\end{array}$ & - & - & $\begin{array}{c}-.085 \\
(.011)\end{array}$ & - & - & $\begin{array}{c}-.116 \\
(.016)\end{array}$ & - & - \\
\hline$c_{b}^{3}$ & $\begin{array}{c}-.010 \\
(.002)\end{array}$ & - & - & $\begin{array}{c}-.019 \\
(.004)\end{array}$ & - & - & $\begin{array}{c}-.025 \\
(.006)\end{array}$ & - & - \\
\hline$c_{a}^{2}$ & $\begin{array}{c}.020 \\
(.008)\end{array}$ & - & - & $\begin{array}{c}.033 \\
(.009)\end{array}$ & - & - & $\begin{array}{c}.035 \\
(.013)\end{array}$ & - & - \\
\hline klh & - & - & $\begin{array}{c}-.006 \\
(.003)\end{array}$ & - & - & $\begin{array}{c}-.002 \\
(.001)\end{array}$ & - & - & $\begin{array}{c}-.003 \\
(.002)\end{array}$ \\
\hline$k l h * t$ & - & - & $\begin{array}{c}-.001 \\
(.002)\end{array}$ & - & - & $\begin{array}{l}-.000 \\
(.001)\end{array}$ & - & - & $\begin{array}{c}.000 \\
(.002)\end{array}$ \\
\hline$k l h * a$ & - & - & $\begin{array}{c}-.002 \\
(.001)\end{array}$ & - & - & $\begin{array}{l}-.000 \\
(.000)\end{array}$ & - & - & $\begin{array}{l}-.000 \\
(.001)\end{array}$ \\
\hline
\end{tabular}

a: The estimate of the covariance matrix is obtained using a Block Bootstrap Procedure (1000 resamples for skill groups (U) and (M) and (H)). The blocks allow for dependence across six adjacent time periods and across eight adjacent cohorts. 
Table 3: Parameter Estimates of Wage Specifications for Skill Group (H) - Males $M$, Full-Time $F(F)$ and Part-Time $F(P)$ Working Females (Standard Errors in Parentheses - Preferred Final Specification Only)

\begin{tabular}{|c|c|c|c|c|c|c|c|c|c|}
\hline Skill Group & \multicolumn{9}{|c|}{ (U) High-Skilled } \\
\hline Quantile & \multicolumn{3}{|c|}{$\theta=0.2$} & \multicolumn{3}{|c|}{$\theta=0.5$} & \multicolumn{3}{|c|}{$\theta=0.8$} \\
\hline Group & $M$ & $F(F)$ & $F(P)$ & $M$ & $F(F)$ & $F(P)$ & $M$ & $F(F)$ & $F(P)$ \\
\hline Specification & $(5)$ & (4) & (4) & $(5)$ & (4) & (4) & (5) & (4) & (4) \\
\hline Intercept & $\begin{array}{l}4.723 \\
(.009)\end{array}$ & $\begin{array}{c}4.509 \\
(.050)\end{array}$ & $\begin{array}{c}4.125 \\
(.176)\end{array}$ & $\begin{array}{c}4.885 \\
(.007)\end{array}$ & $\begin{array}{c}4.687 \\
(.026)\end{array}$ & $\begin{array}{c}4.404 \\
(.098)\end{array}$ & - & $\begin{array}{l}4.872 \\
(.011)\end{array}$ & $\begin{array}{c}4.665 \\
(.112)\end{array}$ \\
\hline$\alpha$ & $\begin{array}{l}.520 \\
(.030)\end{array}$ & $\begin{array}{c}.338 \\
(.061)\end{array}$ & $\begin{array}{c}.038 \\
(.198)\end{array}$ & $\begin{array}{l}.283 \\
(.048)\end{array}$ & $\begin{array}{c}.489 \\
(.052)\end{array}$ & $\begin{array}{c}.293 \\
(.107)\end{array}$ & - & $\begin{array}{c}.682 \\
(.045)\end{array}$ & $\begin{array}{l}.385 \\
(.078)\end{array}$ \\
\hline$\alpha^{2}$ & $\begin{array}{c}-.161 \\
(.024)\end{array}$ & $\begin{array}{c}-.167 \\
(.062)\end{array}$ & $\begin{array}{c}-.025 \\
(.134)\end{array}$ & $\begin{array}{c}.226 \\
(.091)\end{array}$ & $\begin{array}{c}-.230 \\
(.047)\end{array}$ & $\begin{array}{c}-.044 \\
(.083)\end{array}$ & - & $\begin{array}{l}-.447 \\
(.042)\end{array}$ & $\begin{array}{c}-.155 \\
(.061)\end{array}$ \\
\hline$\alpha^{3}$ & $\begin{array}{c}.017 \\
(.006)\end{array}$ & $\begin{array}{c}.024 \\
(.017)\end{array}$ & $\begin{array}{c}.013 \\
(.028)\end{array}$ & $\begin{array}{c}-.204 \\
(.050)\end{array}$ & $\begin{array}{c}.036 \\
(.011)\end{array}$ & $\begin{array}{c}.000 \\
(.018)\end{array}$ & - & $\begin{array}{l}.084 \\
(.010)\end{array}$ & $\begin{array}{c}.022 \\
(.013)\end{array}$ \\
\hline$t$ & $\begin{array}{l}.215 \\
(.086)\end{array}$ & $\begin{array}{c}.516 \\
(.343)\end{array}$ & $\begin{array}{c}1.166 \\
(.847)\end{array}$ & $\begin{array}{c}.417 \\
(.054)\end{array}$ & $\begin{array}{c}.478 \\
(.152)\end{array}$ & $\begin{array}{c}1.254 \\
(.427)\end{array}$ & - & $\begin{array}{c}.630 \\
(.192)\end{array}$ & $\begin{array}{c}.432 \\
(.454)\end{array}$ \\
\hline$t^{2}$ & $\begin{array}{c}-.765 \\
(.299)\end{array}$ & $\begin{array}{l}-1.056 \\
(.965)\end{array}$ & $\begin{array}{c}-3.223 \\
(2.237)\end{array}$ & $\begin{array}{r}-1.199 \\
(.188)\end{array}$ & $\begin{array}{r}-1.021 \\
(.481)\end{array}$ & $\begin{array}{c}-4.230 \\
(1.243)\end{array}$ & - & $\begin{array}{l}-2.089 \\
(.668)\end{array}$ & $\begin{array}{c}-1.587 \\
(1.144)\end{array}$ \\
\hline$t^{3}$ & $\begin{array}{c}.834 \\
(.399)\end{array}$ & $\begin{array}{c}.642 \\
(1.141)\end{array}$ & $\begin{array}{c}2.890 \\
(2.671)\end{array}$ & $\begin{array}{c}1.417 \\
(.264)\end{array}$ & $\begin{array}{c}.773 \\
(.630)\end{array}$ & $\begin{array}{c}4.580 \\
(1.522)\end{array}$ & - & $\begin{array}{l}2.605 \\
(.849)\end{array}$ & $\begin{array}{c}1.468 \\
(1.388)\end{array}$ \\
\hline$t^{4}$ & $\begin{array}{c}-.337 \\
(.226)\end{array}$ & $\begin{array}{c}-.011 \\
(.593)\end{array}$ & $\begin{array}{c}-.898 \\
(1.447)\end{array}$ & $\begin{array}{c}-.651 \\
(.155)\end{array}$ & $\begin{array}{c}-.170 \\
(.352)\end{array}$ & $\begin{array}{l}-2.058 \\
(.810)\end{array}$ & - & $\begin{array}{l}-1.313 \\
(.459)\end{array}$ & $\begin{array}{c}-.477 \\
(.754)\end{array}$ \\
\hline$t^{5}$ & $\begin{array}{c}.043 \\
(.045)\end{array}$ & $\begin{array}{c}-.050 \\
(.112)\end{array}$ & $\begin{array}{c}.064 \\
(.288)\end{array}$ & $\begin{array}{c}.102 \\
(.032)\end{array}$ & $\begin{array}{c}-.005 \\
(.069)\end{array}$ & $\begin{array}{c}.332 \\
(.155)\end{array}$ & - & $\begin{array}{c}.232 \\
(.089)\end{array}$ & $\begin{array}{c}.040 \\
(.149)\end{array}$ \\
\hline$c_{b}^{2}$ & - & - & - & - & - & - & - & - & - \\
\hline$c_{b}^{3}$ & - & - & - & - & - & - & - & - & - \\
\hline$c_{a}^{2}$ & $\begin{array}{c}.019 \\
(.011)\end{array}$ & - & - & $\begin{array}{c}-.020 \\
(.011)\end{array}$ & - & - & - & - & - \\
\hline klh & - & - & $\begin{array}{c}-.010 \\
(.003)\end{array}$ & - & - & $\begin{array}{c}-.007 \\
(.002)\end{array}$ & - & - & $\begin{array}{c}-.007 \\
(.002)\end{array}$ \\
\hline$k l h * t$ & - & - & $\begin{array}{c}-.003 \\
(.002)\end{array}$ & - & - & $\begin{array}{c}.004 \\
(.001)\end{array}$ & - & - & $\begin{array}{c}.004 \\
(.002)\end{array}$ \\
\hline$k l h * a$ & - & - & $\begin{array}{c}-.002 \\
(.001)\end{array}$ & - & - & $\begin{array}{c}-.002 \\
(.001)\end{array}$ & - & - & $\begin{array}{c}.000 \\
(.001)\end{array}$ \\
\hline
\end{tabular}

a: The estimate of the covariance matrix is obtained using a Block Bootstrap Procedure (1000 resamples for skill groups (U) and (M) and (H)). The blocks allow for dependence across six adjacent time periods and across eight adjacent cohorts. 
Figure 1: Aggregate Trends of Levels and Growth Rates of Log Real Wages $1975-1995$

Males, Full-Time Employed Females, Part-Time Employed Females

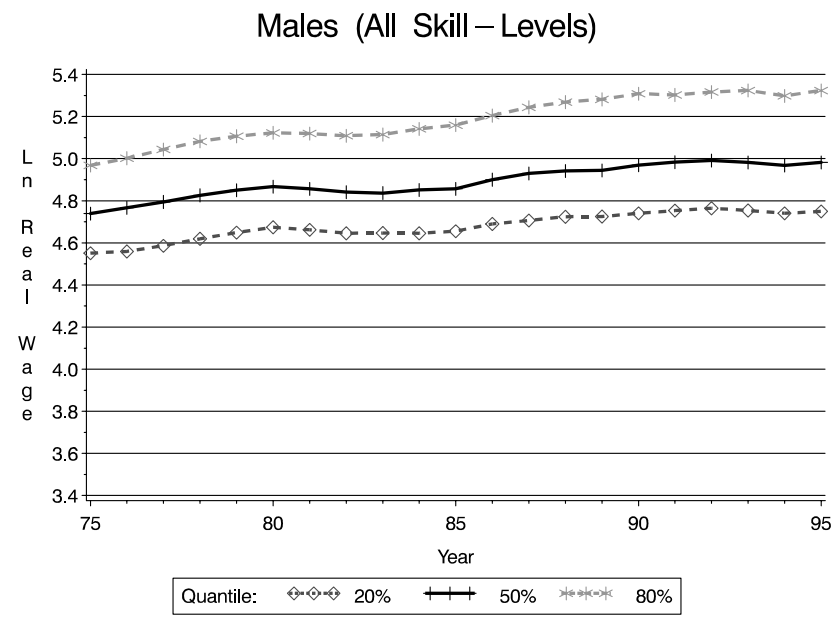

Females, Full-Time Employed (All Skill-Levels)

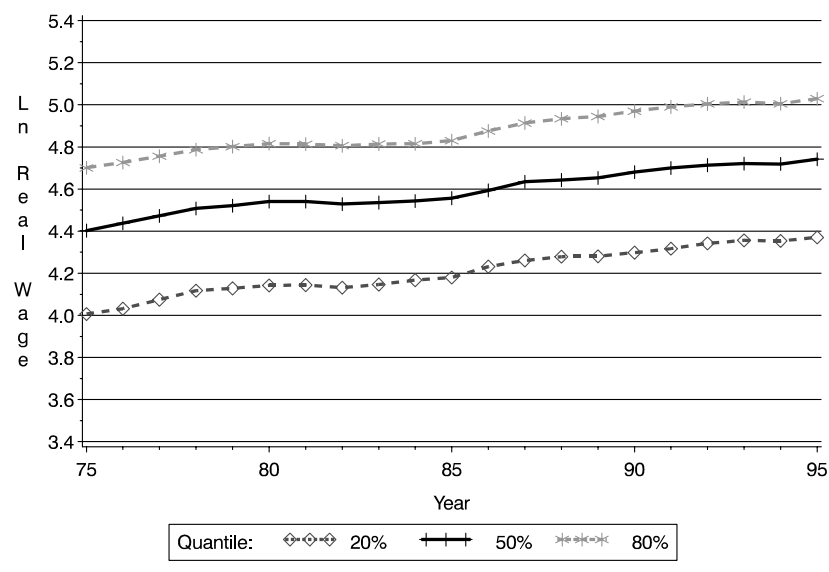

Females, Part-Time Employed (All Skill-Levels)

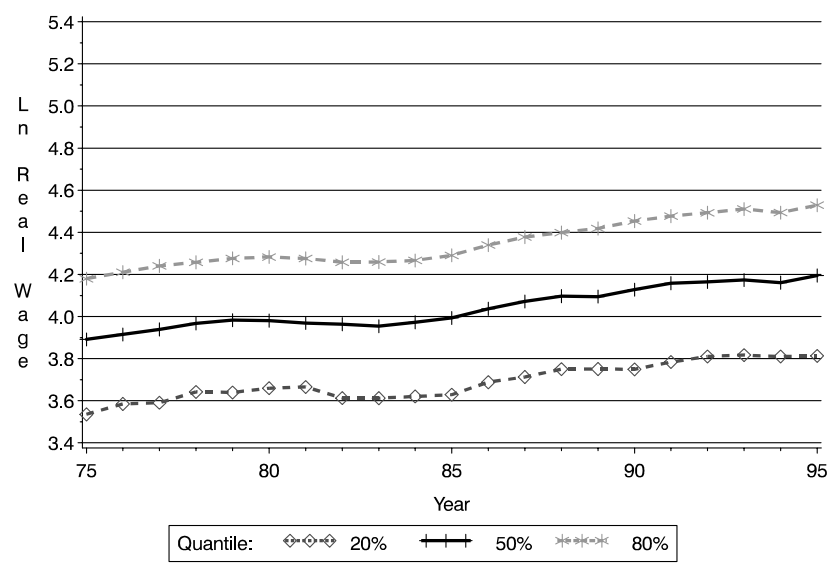

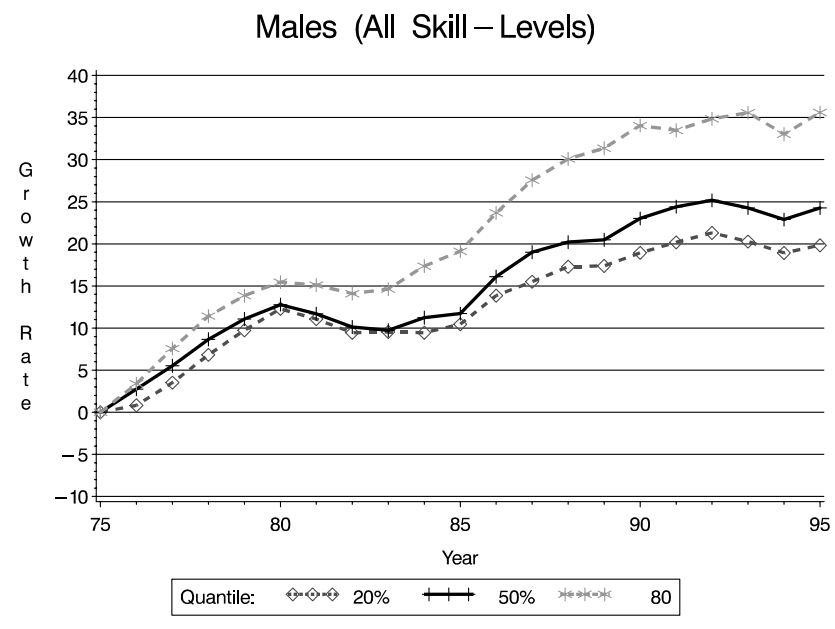

Females, Full-Time Employed (All Skill-Levels)

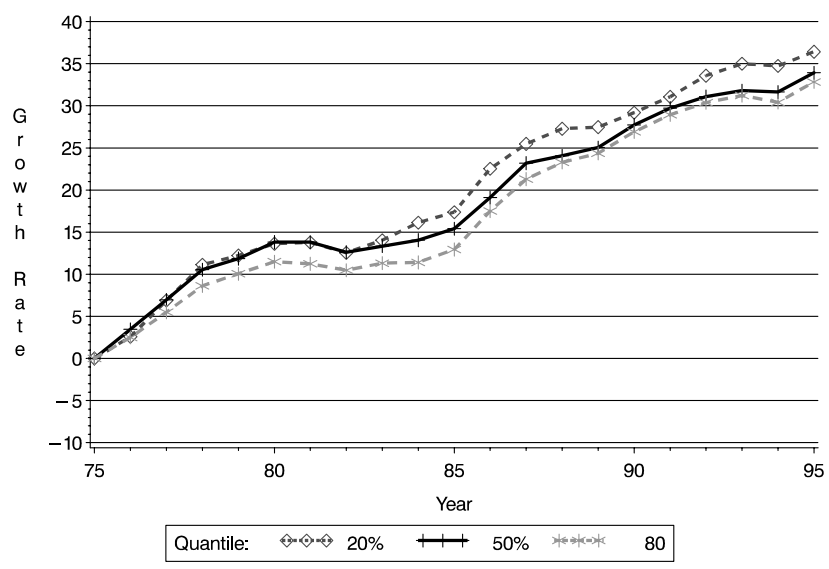

Females, Part-Time Employed (All Skill-Levels)

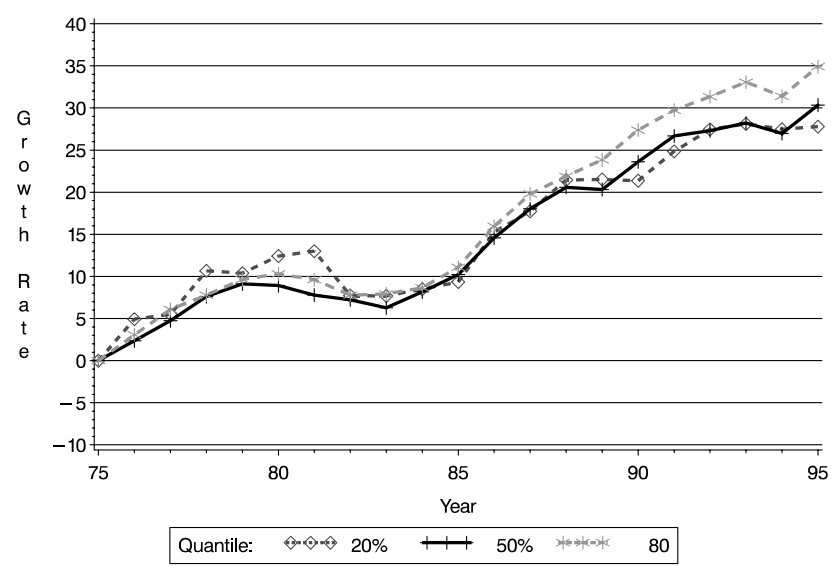


Figure 2: Unconditional Growth of Log Real Wages by Skill-Level $1975-1995$

\section{Males}
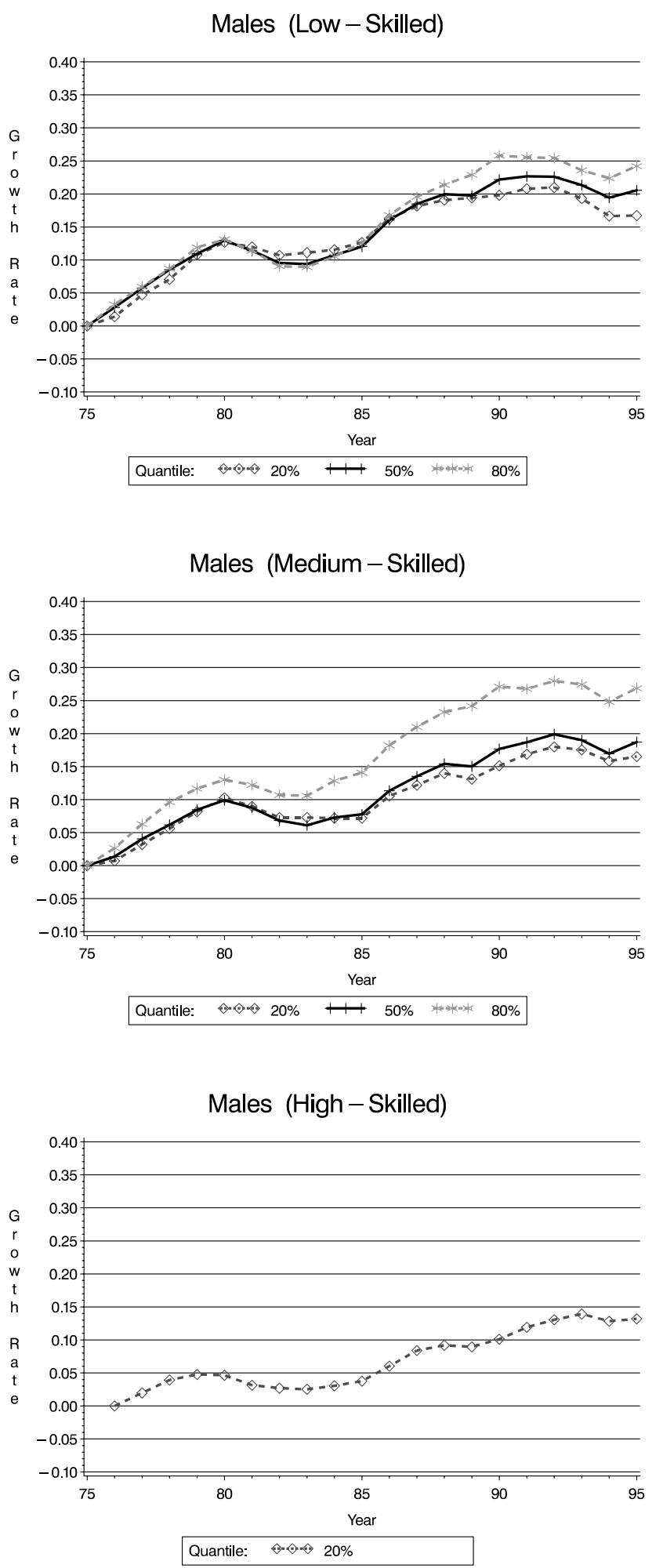
Figure 3: Unconditional Growth of Log Real Wages by Skill-Level

$1975-1995$

Full-Time Employed Females, Part-Time Employed Females

Females, Full-Time Employed (Low-Skilled)

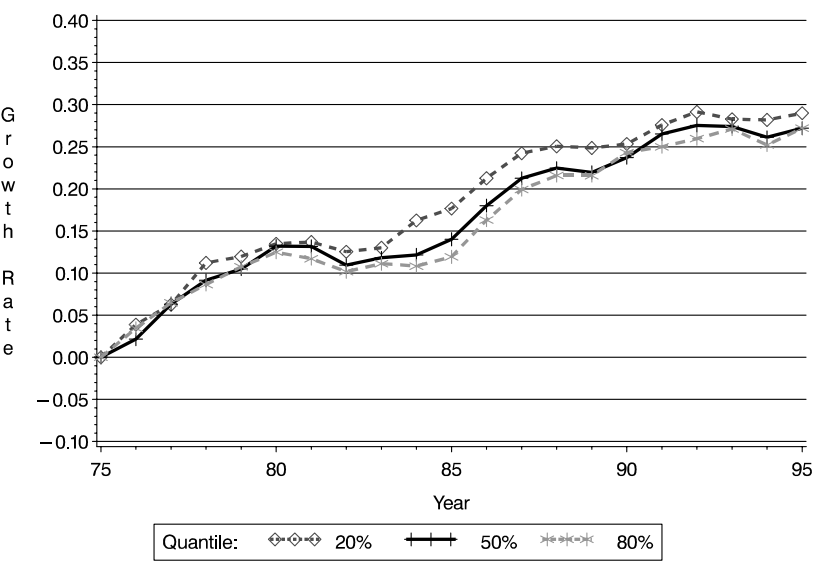

Females, Full-Time Employed (Medium-Skilled)

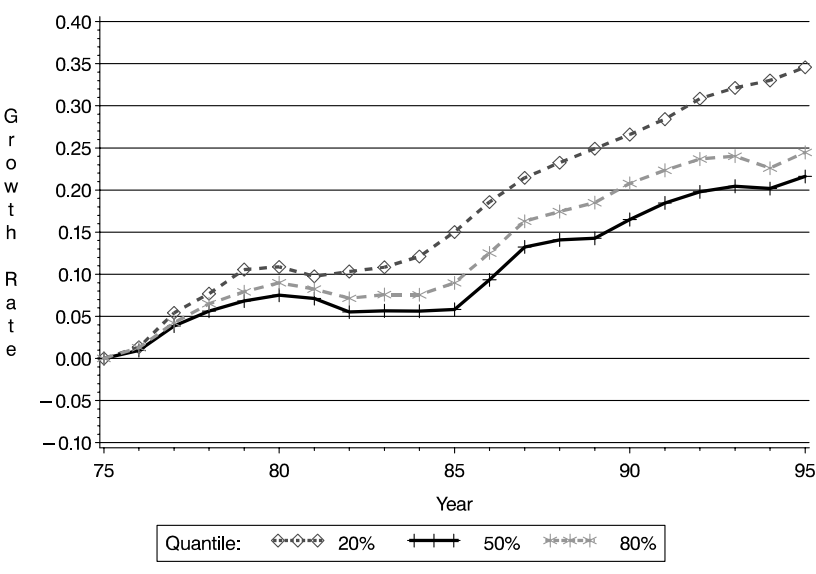

Females, Full-Time Employed (High-Skilled)

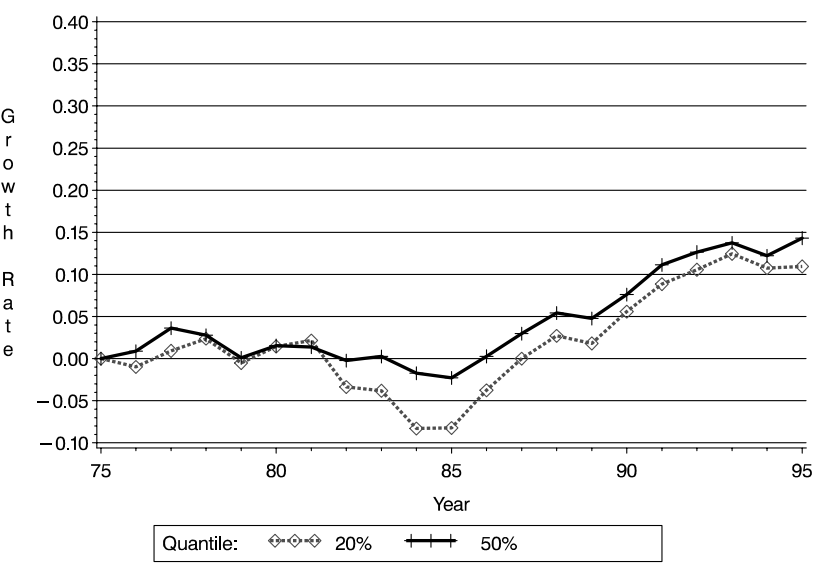

Females, Part-Time Employed (Low-Skilled)

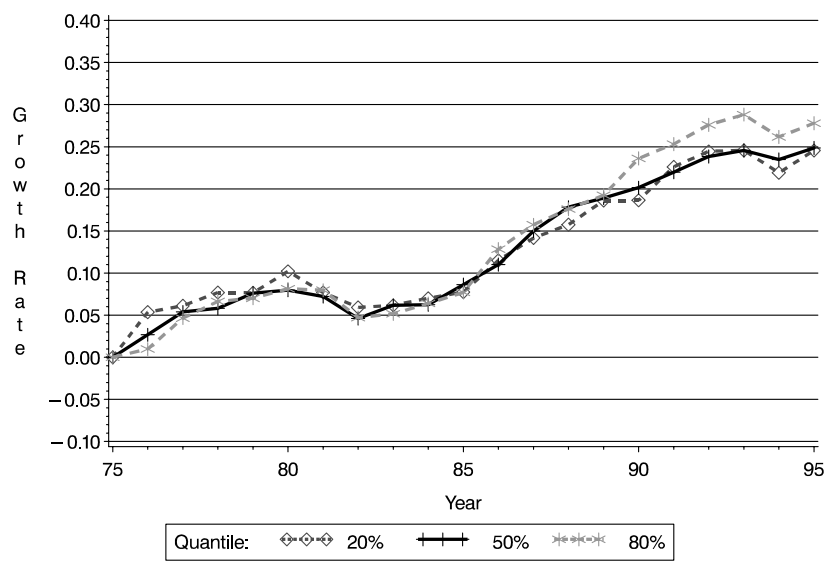

Females, Part-Time Employed (Medium - Skilled)

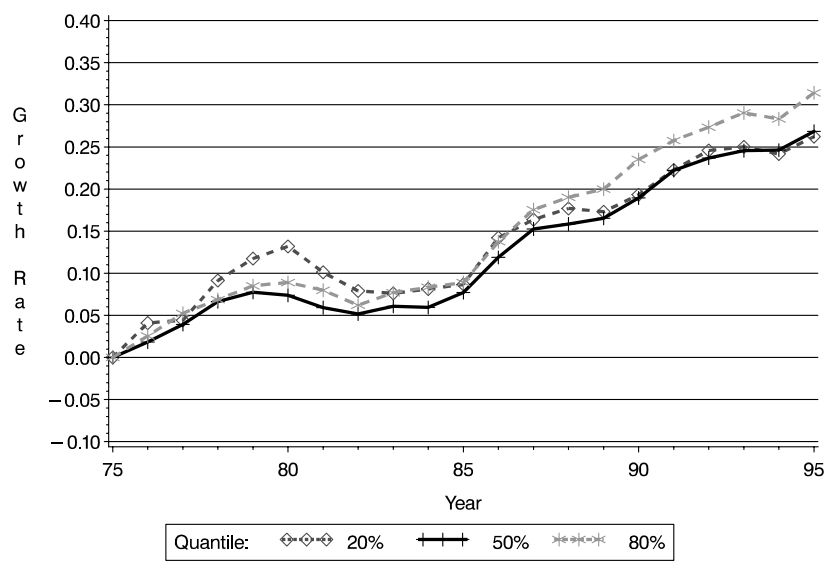

Females, Part-Time Employed (High-Skilled)

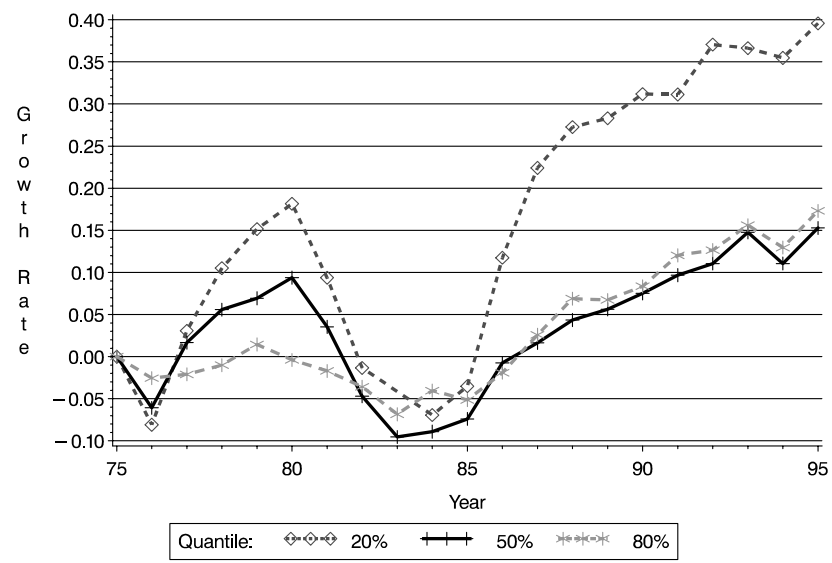


Figure 4: Differences of Unconditional Growth of Log Real Wages by Skill-Level $1975-1995$

Females, Full-Time Employed - Males

Females, Part-Time Employed - Males

Females, Full-Time Employed - Males (Low-Skilled)

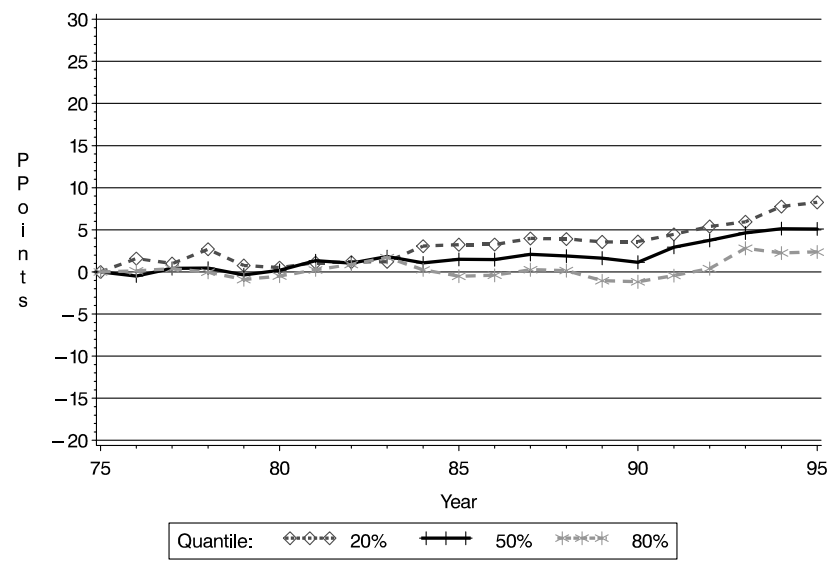

Females, Full-Time Employed - Males (Med. - Skilled)

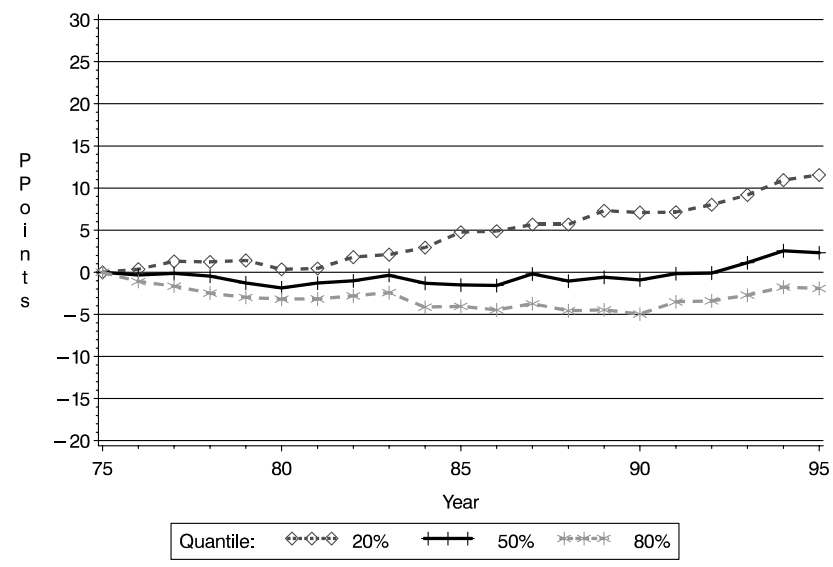

Females, Full-Time Empl. (High-Skilled) - Males (Med. - Skilled)

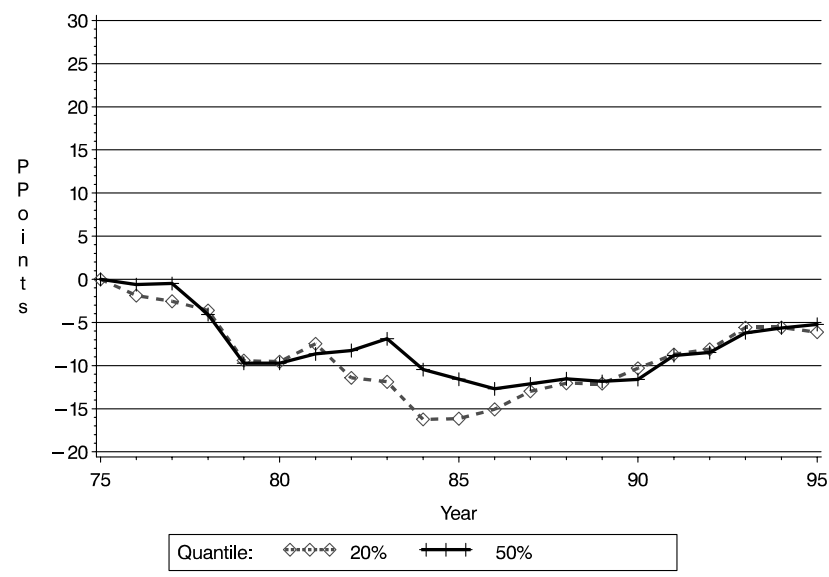

Females, Part-Time Employed - Males (Low-Skilled)

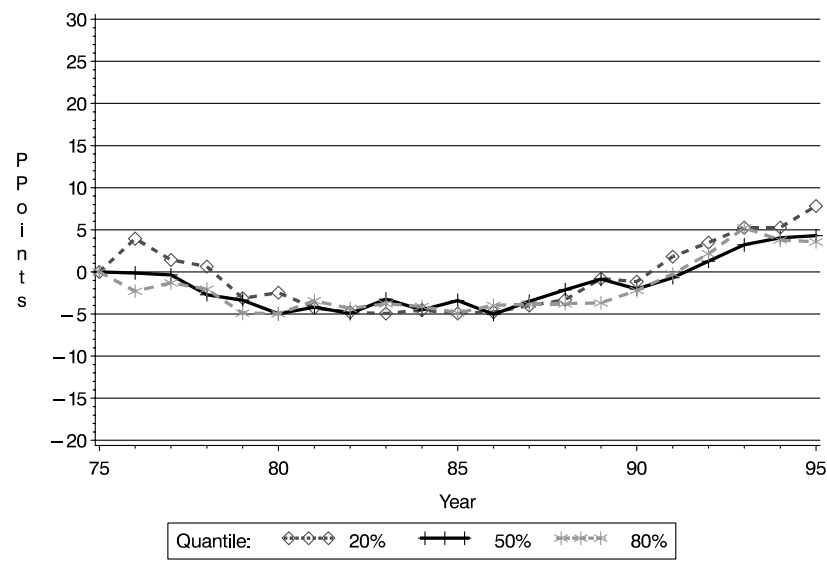

Females, Part-Time Employed - Males (Med.-Skilled)

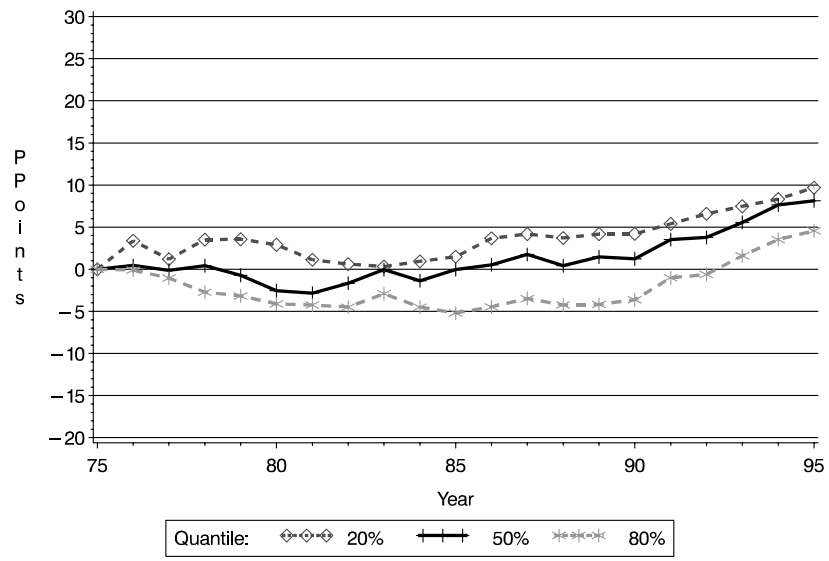

Females, Part-Time Empl. (High-Skilled) - Males (Med. - Skilled)

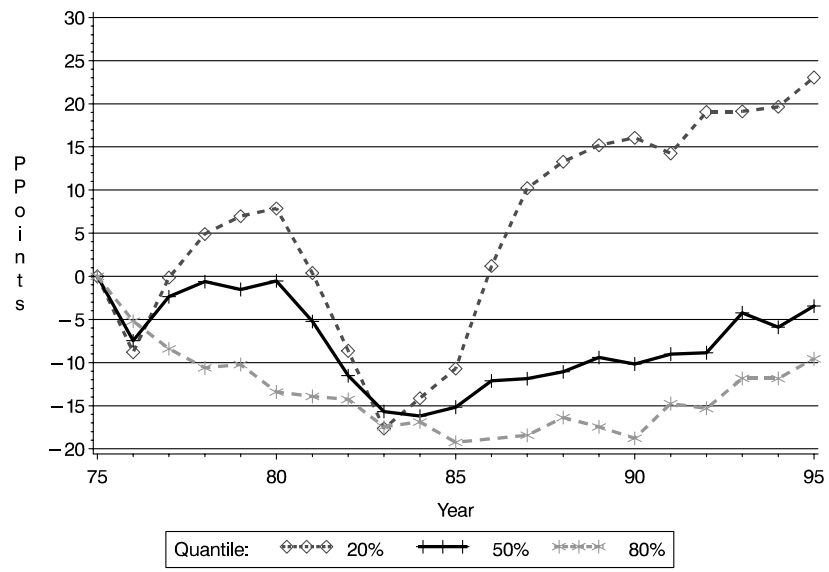


Figure 5: Life-Cycle Profiles of Wages by Skill-Level

$1975-1995$

Males and Full-Time Employed Females

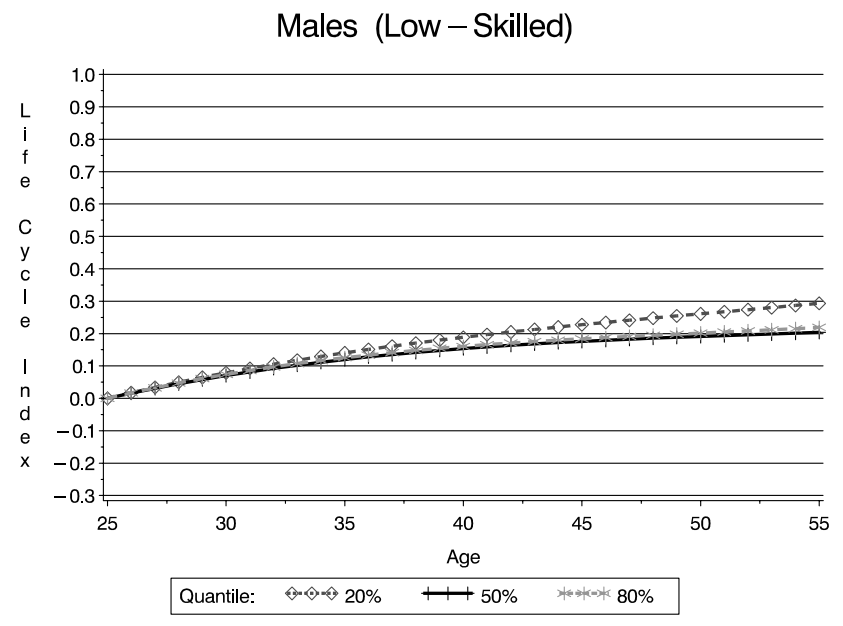

Males (Medium-Skilled)

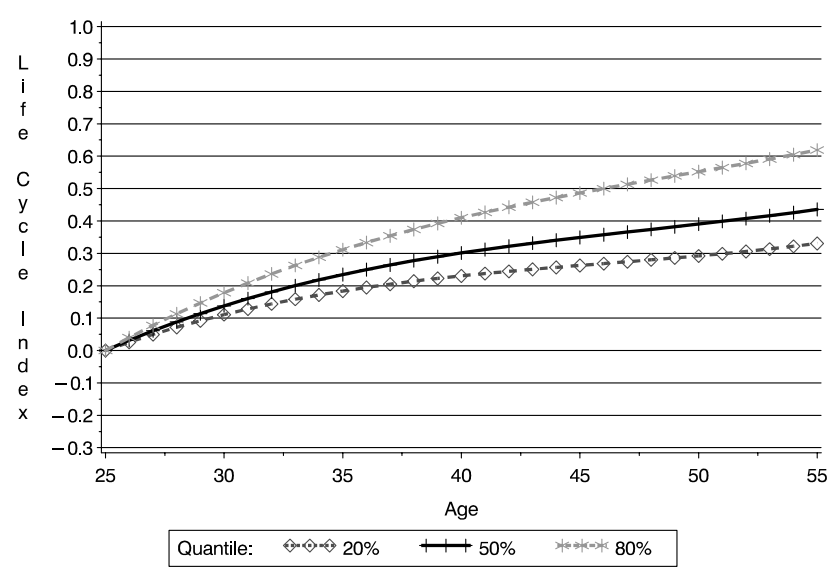

Males (High-Skilled)

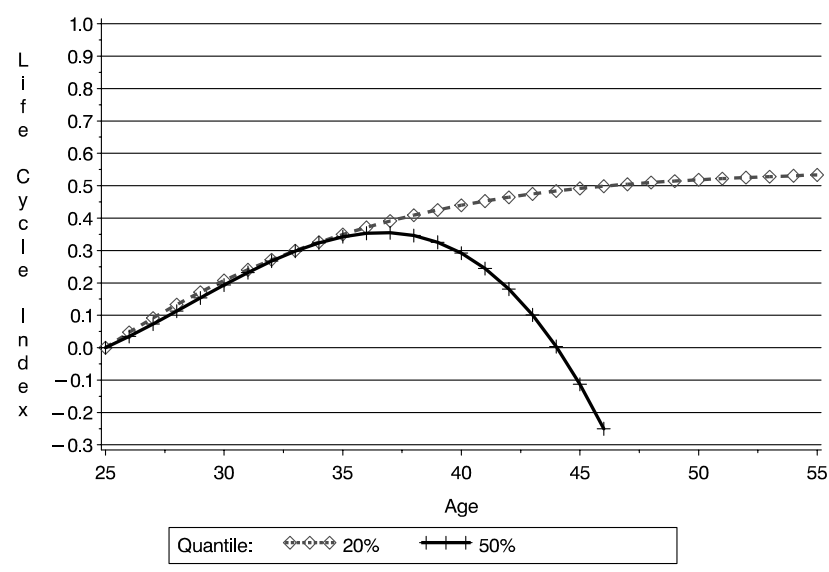

Females, Full-Time Employed (Low-Skilled)

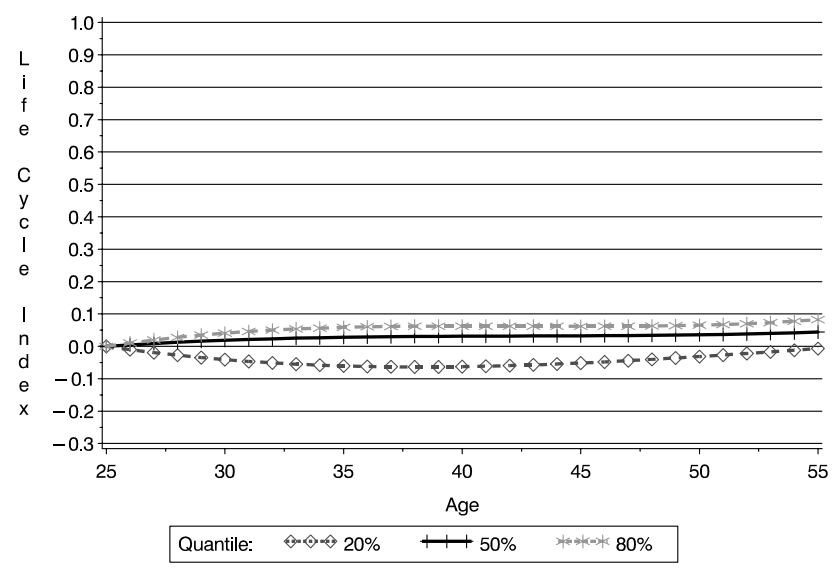

Females, Full-Time Employed (Medium-Skilled)

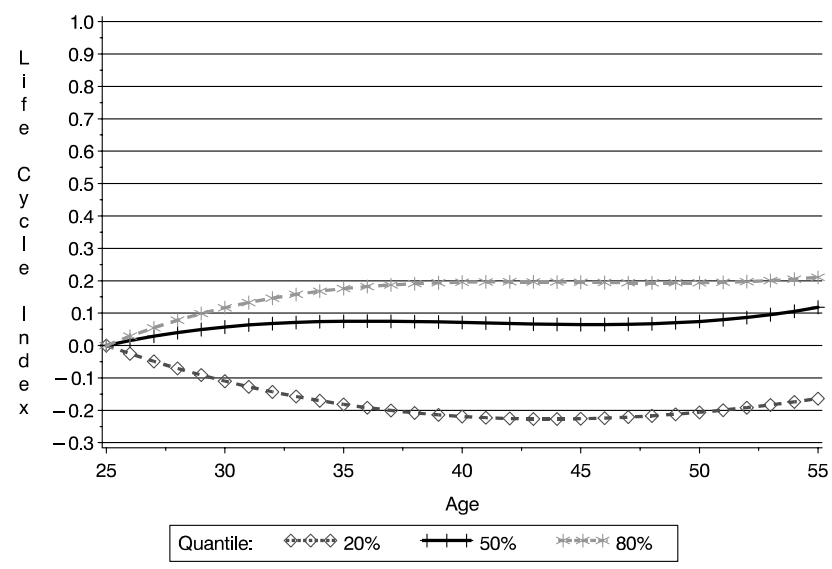

Females, Full-Time Employed (High-Skilled)

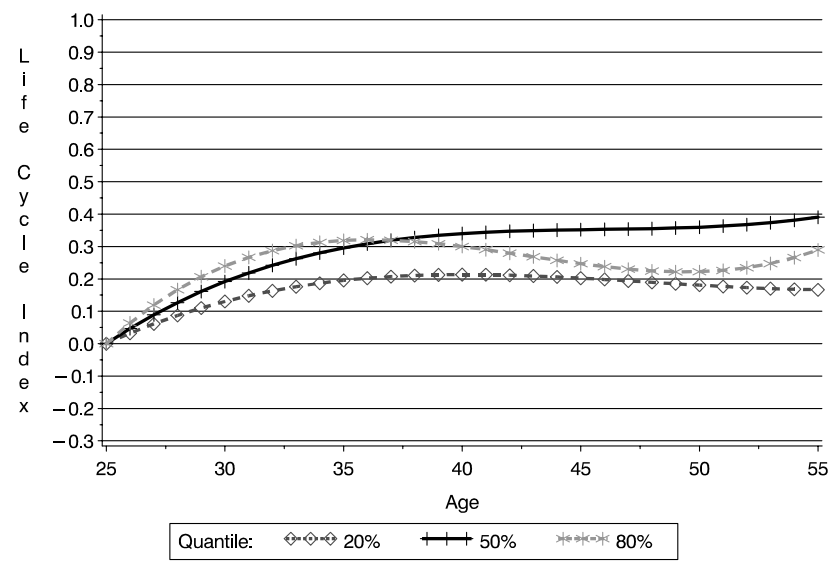




\section{Figure 6: Life-Cycle Profiles of Wages by Skill-Level $1975-1995$ \\ Males and Part-Time Employed Females}

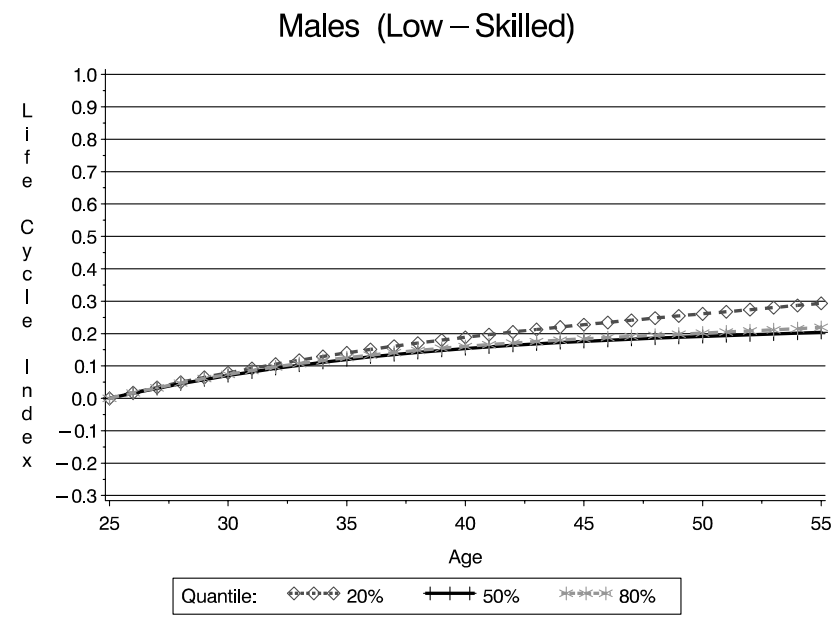

Males (Medium - Skilled)

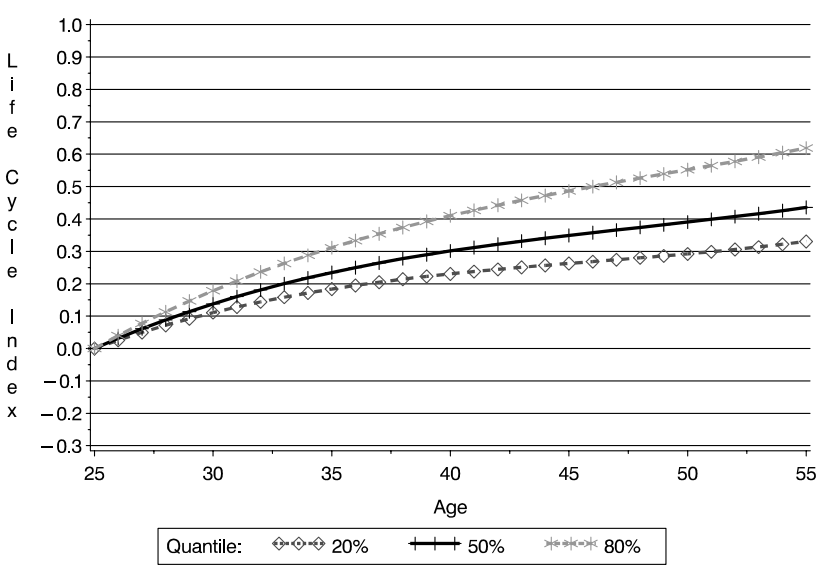

Males (High - Skilled)

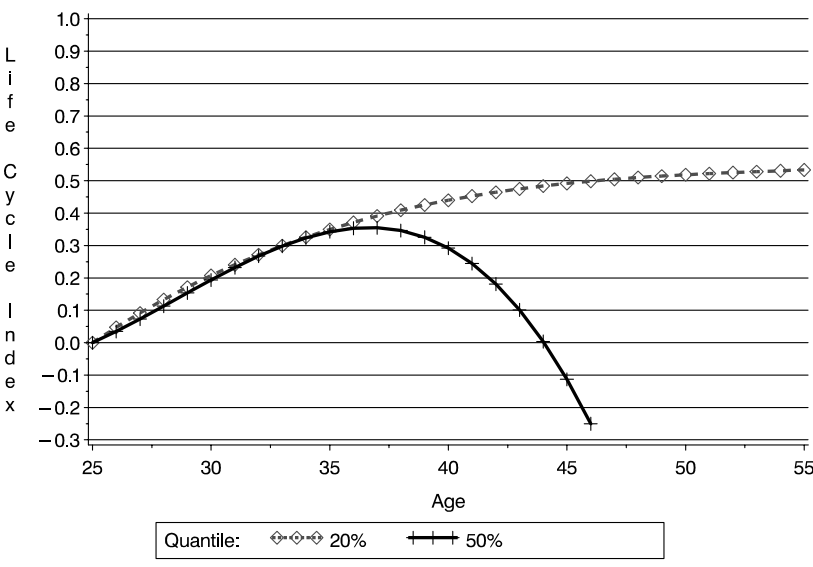

Females, Part-Time Employed (Low-Skilled)

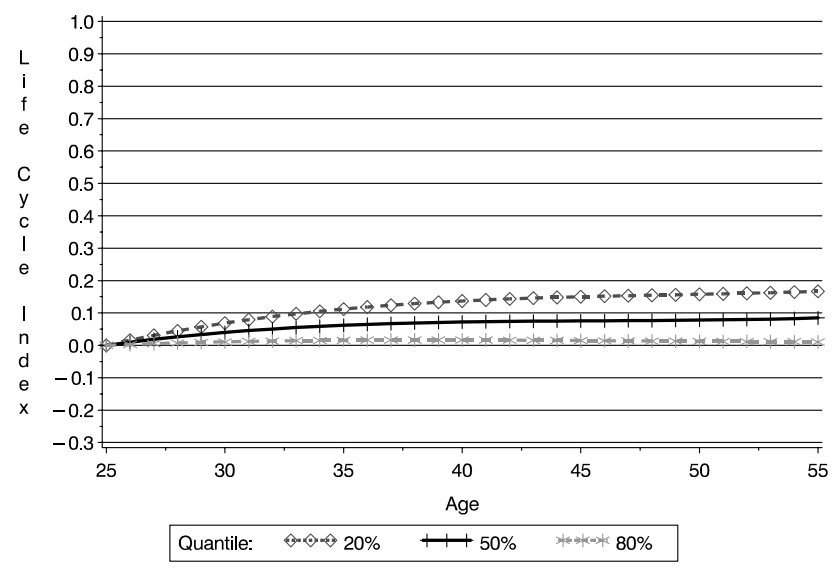

Females, Part-Time Employed (Medium-Skilled)

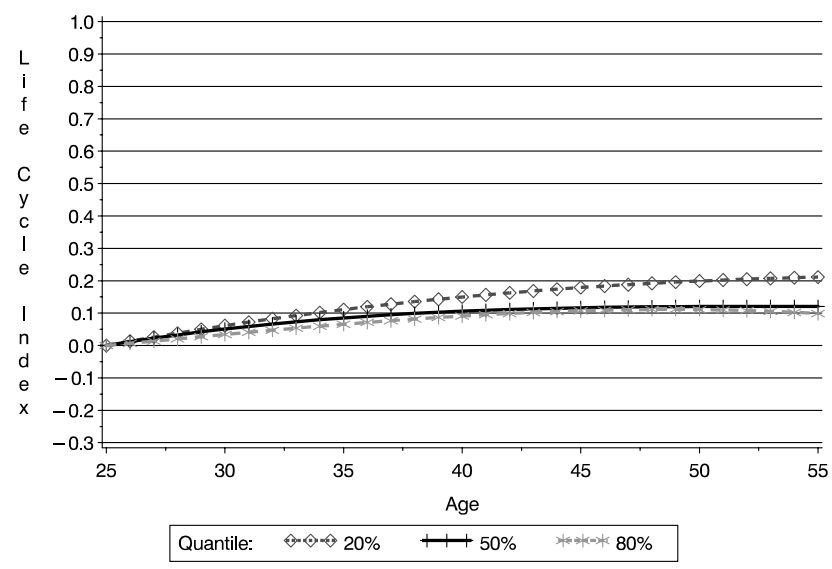

Females, Part-Time Employed (High-Skilled)

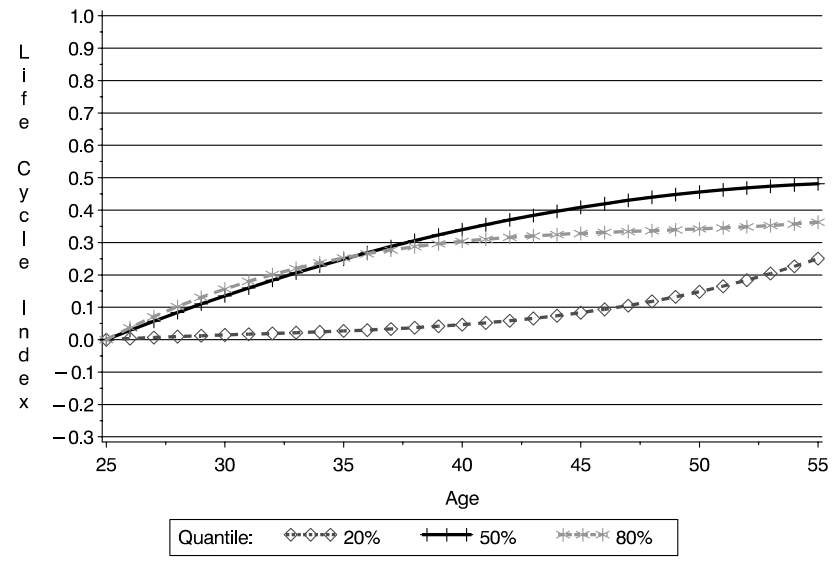


Figure 7: Time Trends of Wages by Skill-Level

$1975-1995$

Males and Full-Time Employed Females

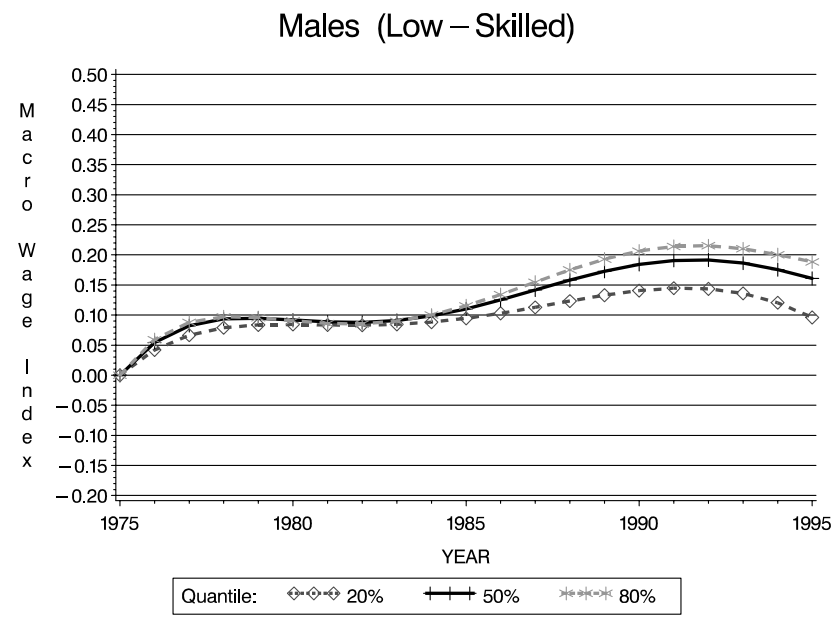

Males (Medium - Skilled)

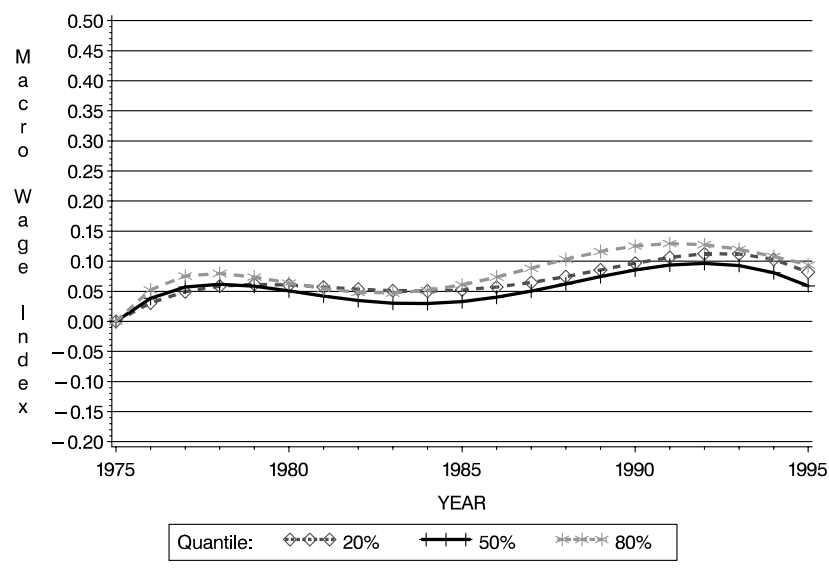

Males (High - Skilled)

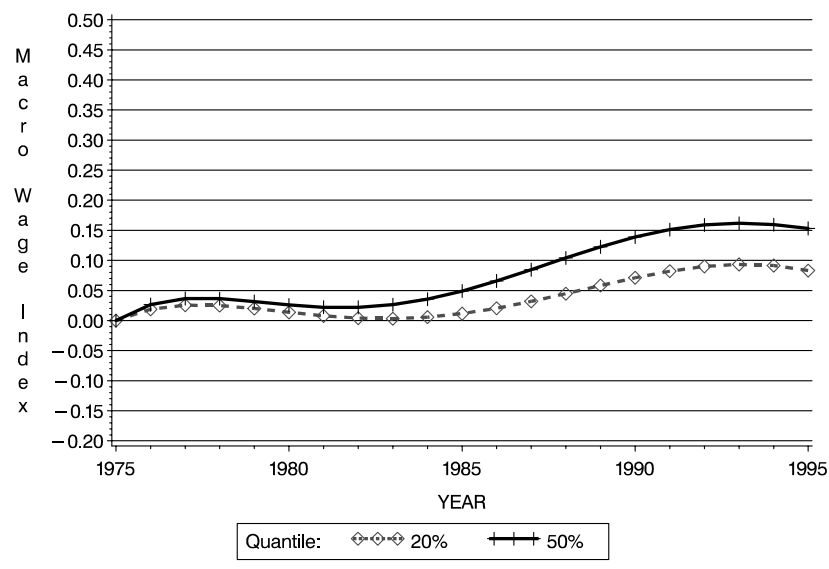

Females, Full-Time Employed (Low-Skilled)

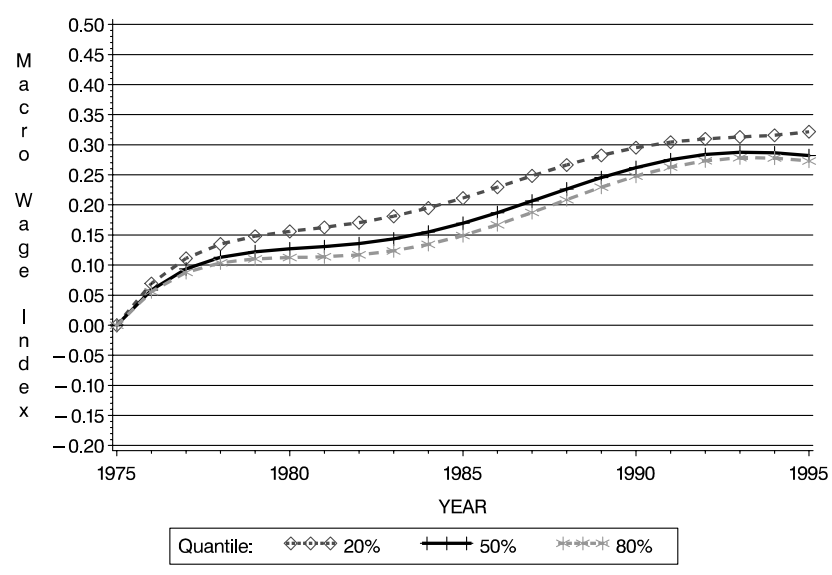

Females, Full-Time Employed (Medium-Skilled)

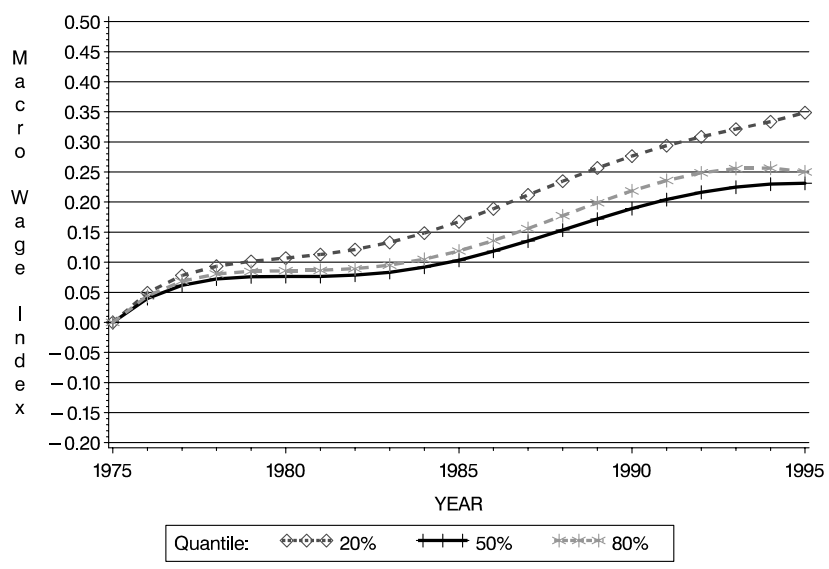

Females, Full-Time Employed (High-Skilled)

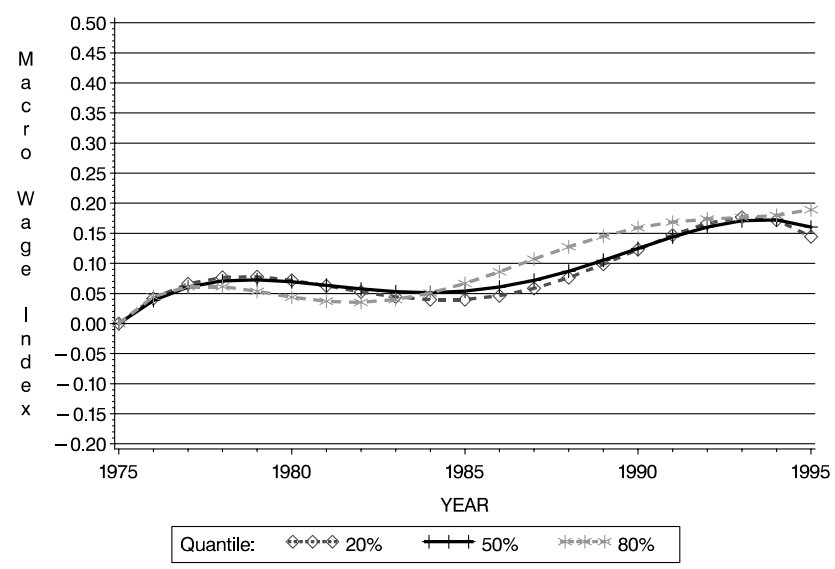


Figure 8: Time Trends of Wages by Skill-Level

$1975-1995$

Males and Part-Time Employed Females

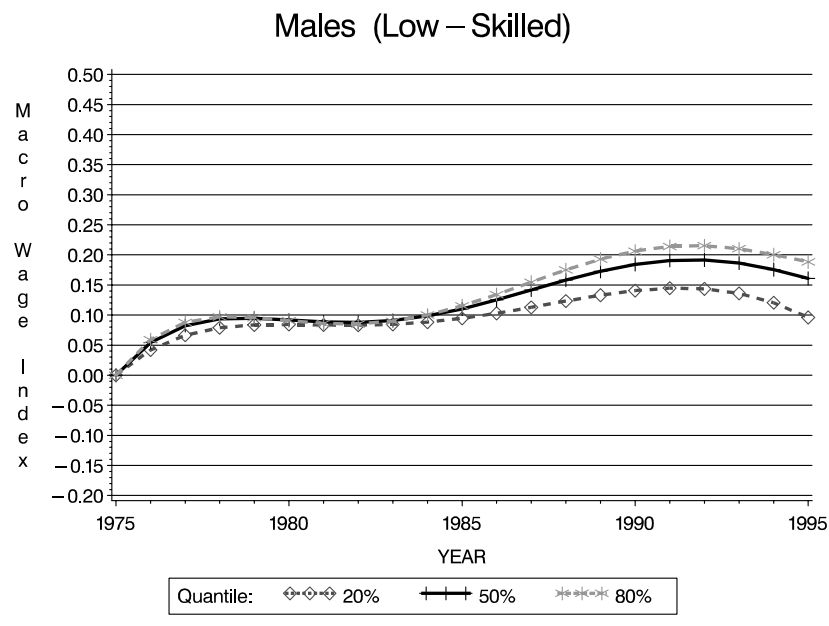

Males (Medium - Skilled)

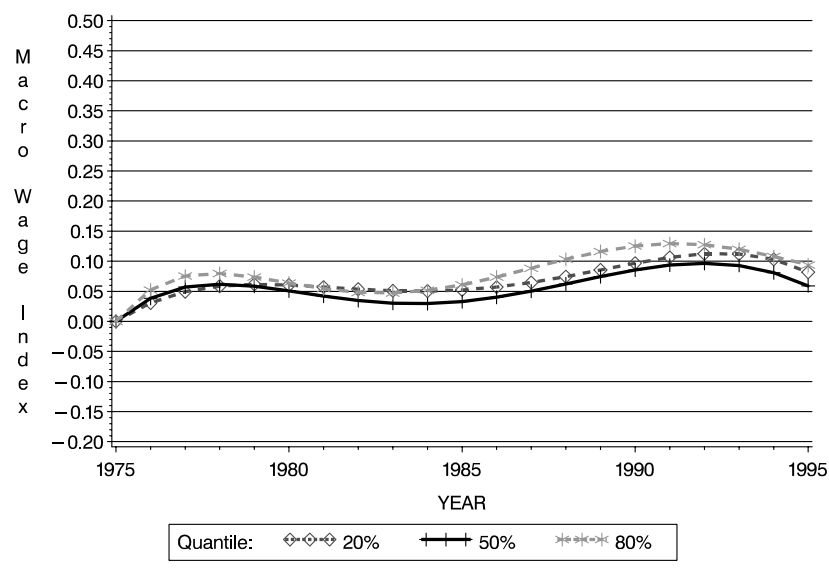

Males (High - Skilled)

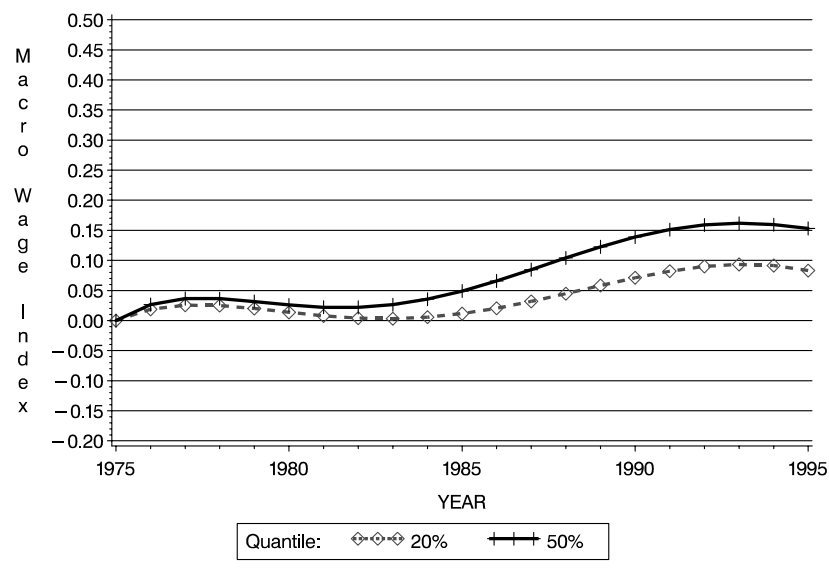

Females, Part-Time Employed (Low-Skilled)

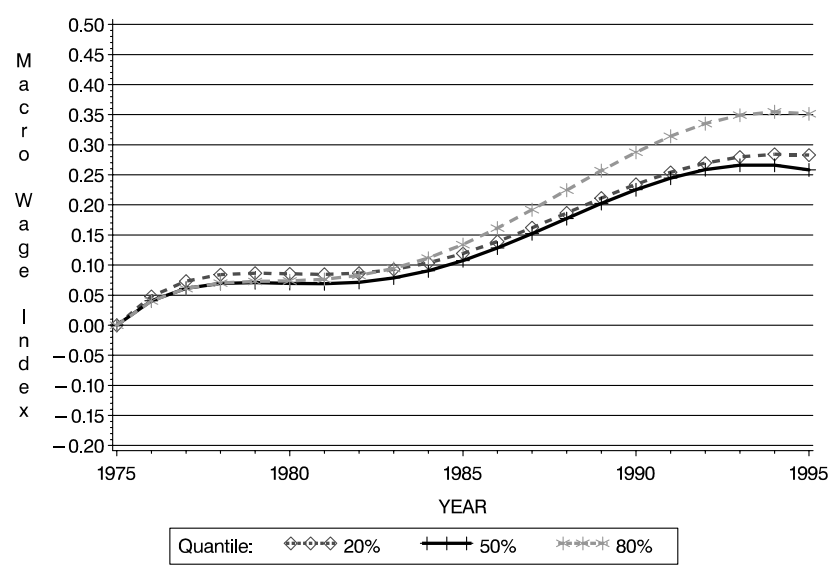

Females, Part-Time Employed (Medium - Skilled)

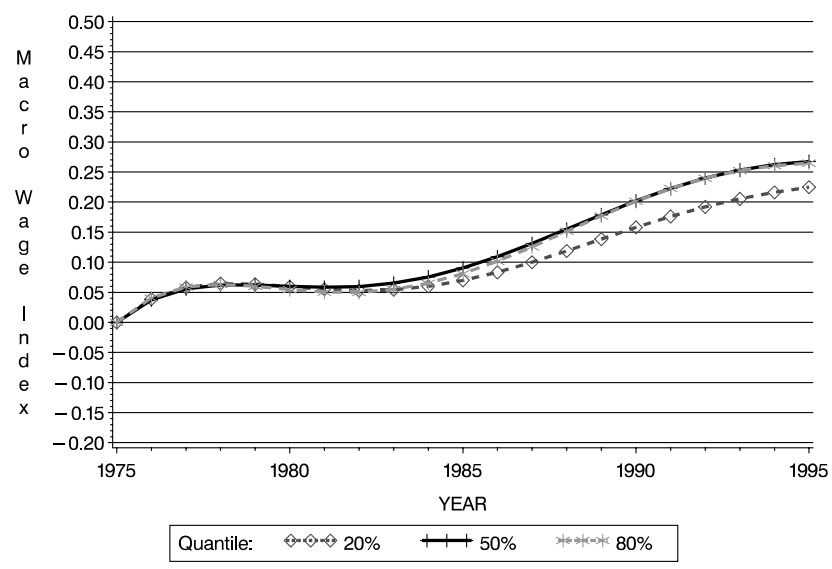

Females, Part-Time Employed (High-Skilled)

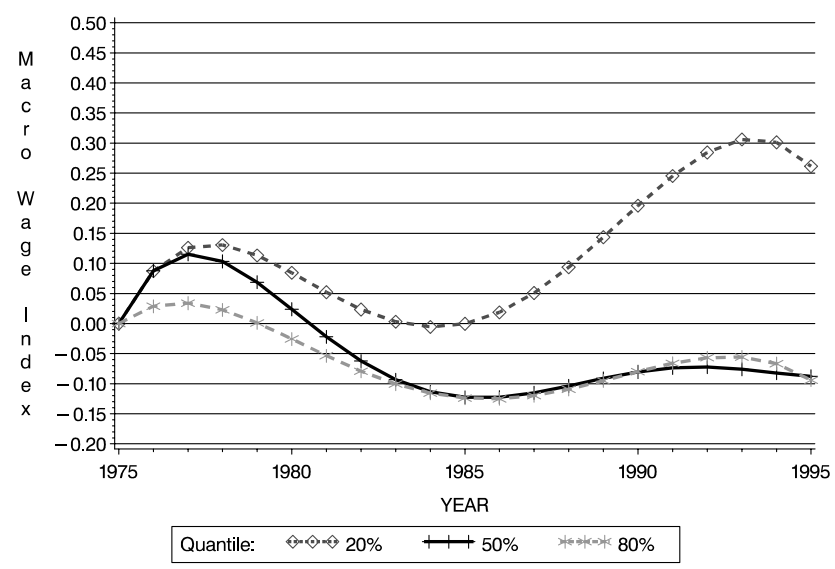


Figure 9: Differences in Estimated Time Trends by Skill Level

$1975-1995$

Females, Full-Time Employed - Males

Females, Part-Time Employed - Males

Females, Full-Time Employed - Males (Low-Skilled)

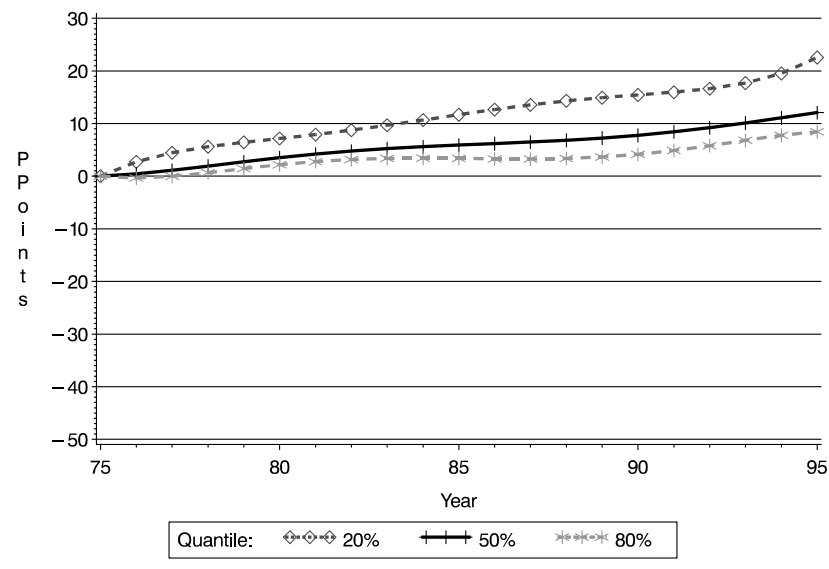

Females, Fulltime-Employed - Males (Med. - Skilled)

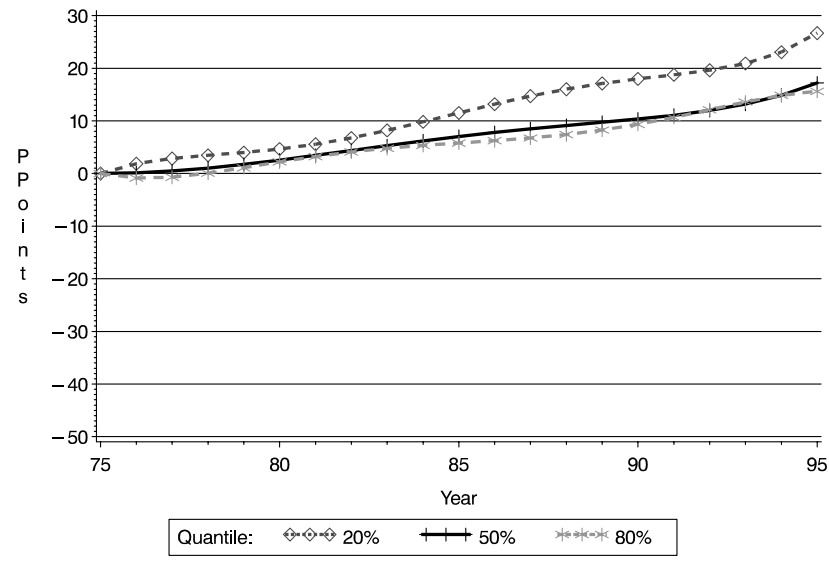

Females, Full-Time Empl. (High-Skilled) - Males (Med. - Skilled)

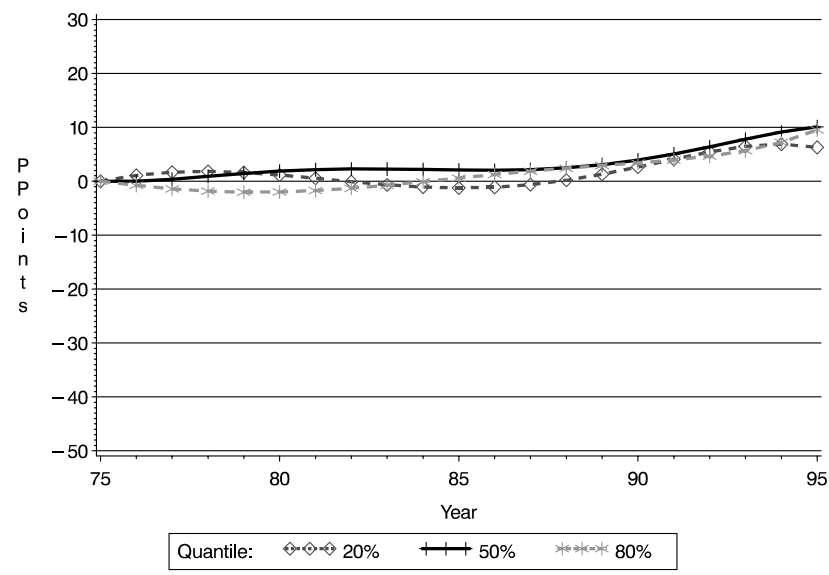

Females, Part-Time Employed - Males (Low-Skilled)

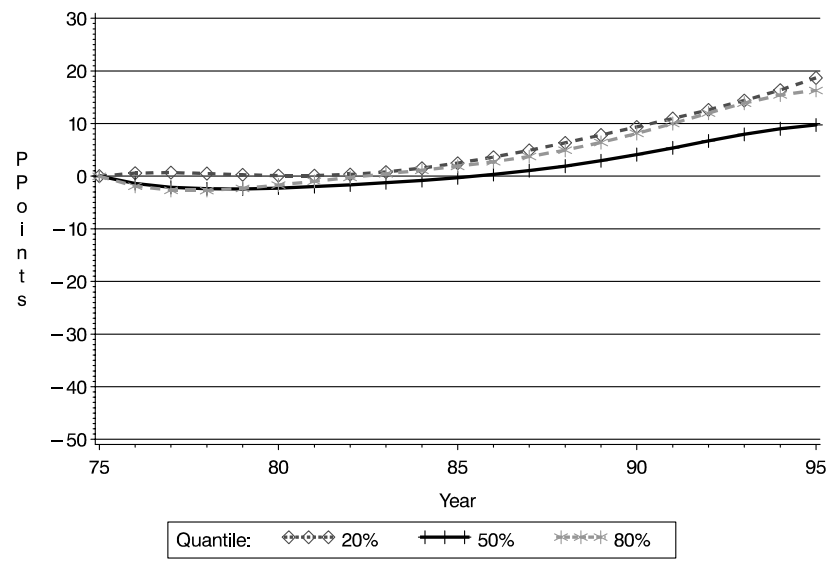

Females, Part-Time Employed - Males (Med.-Skilled)

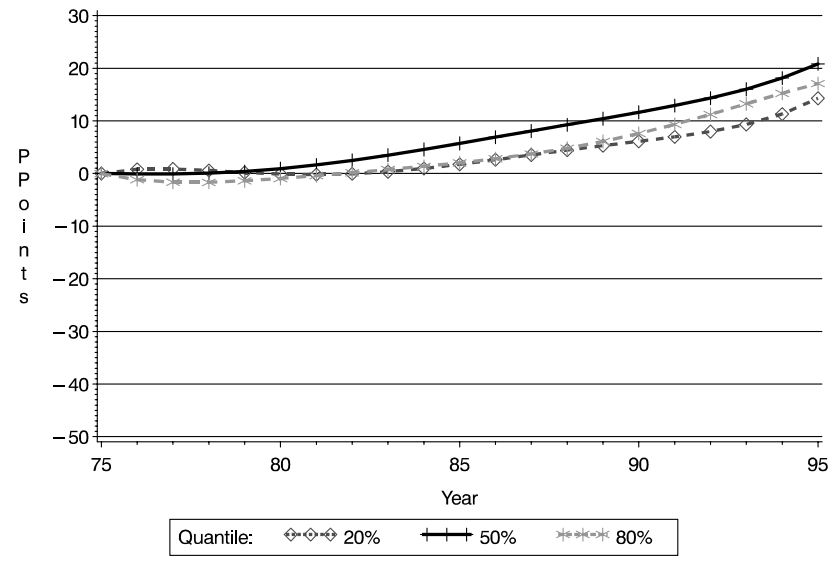

Females, Part-Time Empl. (High-Skilled) - Males (Med. - Skilled)

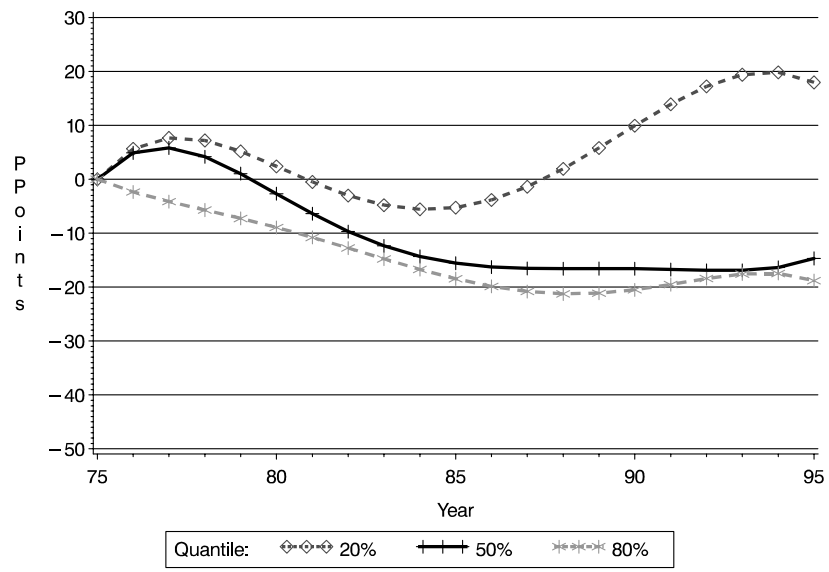




\section{References}

Bender, S., Hilzendegen, J., Rohwer, G., and Rudolph, H. (1996) Die IABBeschäftigtenstichprobe 1975-1990. Beiträge zur Arbeitsmarkt- und Berufsforschung, 197, Institut für Arbeitsmarkt- und Berufsforschung der Bundesanstalt für Arbeit (IAB) Nürnberg.

Blau, F. and Kahn, L. (1996) Wage Structure and Gender Earnings Differentials: an International Comparison. Economica, 63, S29-S62.

Blau, F. and Kahn, L. (1997) Swimming Upstream: Trends in the Gender Wage Differential in the 1980s. Journal of Labor Economics, 15, 1-42.

Boockmann, B. and Steiner, V. (2000) Cohort Effects and the Returns to Education in West Germany, Discussion Paper No. 00-05, Centre for European Economic Research (ZEW), Mannheim.

Chamberlain, G. (1994) Quantile Regression, Censoring, and the Structure of Wages. In: Sims, C., (ed.), Advances in Econometrics: Sixth World Congress. Econometric Society Monograph, Volume 1.

Fitzenberger, B. (1998) The Moving Blocks Bootstrap and Robust Inference for Linear Least Squares and Quantile Regressions. Journal of Econometrics, 82, $235-287$.

Fitzenberger, B. (1999) Wages and Employment Across Skill Groups: An Analysis for West Germany. Physica-Verlag, Heidelberg.

Fitzenberger, B., Hujer, R., MaCurdy, T., and Schnabel, R. (1995) The Dynamic Structure of Wages in Germany 1976-1984, A Cohort Analysis. Center for International Labor Economics, Discussion Paper No. 22, University of Kon$\operatorname{stanz}$

Fitzenberger, B. and MaCurdy, T. E. (1996) Block Bootstrap Procedures for Robust Inference on Regression Estimates based on Grouped Data from Time Series of Cross-sections: Theoretical Results. Unpublished Manuscript, University of Konstanz and Stanford University.

Gosling, A., Machin, S., and Meghir, C. (1996) What Has Happened to the Wages of Men since 1966? In: Hills, J., (ed.), New Inequalities. The Changing Distribution of Income and Wealth in the United Kingdom. Cambridge University Press, Cambridge.

Heckman, J. J. and Robb, R. (1985) Using Longitudinal Data to Estimate Age, Period and Cohort Effects in Earnings Equations. In: Mason, W. and Fienberg, S., (eds.), Cohort Analysis in Social Research. New York.

Hunt, J. (1997) The Transition in East Germany: When is a Ten Point Fall in the Gender Wage Gap bad News? NBER Working Paper No. 6167.

Joshi, H. and Paci, P. (1998) Unequal Pay for Women and Men: Evidence from the British Birth Cohort Studies. MIT Press, Cambridge. 
Koenker, R. and Bassett, G. (1978) Regression Quantiles. Econometrica, 46, 3350.

MaCurdy, T.E. and Mroz, T. (1995) Measuring Macroeconomic Shifts in Wages from Cohort Specifications. Unpublished Manuscript, Stanford University and University of North Carolina.

Lauer, Ch. (2000) Gender Wage Gap in West Germany: How far Do Gender Differences in Human Capital Matter? Discussion Paper No. 00-07, Center for European Economic Research (ZEW), Mannheim.

Möller, J. (1999) Changes of the Structure of Wages and Employment with Respect to Qualifications in Germany. Jahrbücher für Nationalökonomie und Statistik, $219,8-31$.

OECD (1993) Economic Outlook - Earnings Inequality: Changes in the 1980's. Chapter 5. Paris.

OECD (1996) Economic Outlook - Earnings Inequality, Low Paid Employment and Earnings Mobility. Chapter 3. Paris.

OECD (1999) Economic Outlook. Paris.

Powell, J.L. (1986) Censored Regression Quantiles. Journal of Econometrics, 32, $143-155$.

Prey, H. (1999) Die Entwicklung der geschlechtsspezifischen Lohndifferenz in Westdeutschland 1984-96. Diskussionspapier Nr. 57 des Forschungsinstituts für Arbeit und Arbeitsrecht an der Universität St. Gallen.

Steiner, V. and Lauer, Ch. (2000) Private Erträge von Bildungsinvestitionen in Deutschland, Discussion Paper No. 00-18, Centre for European Economic Research (ZEW), Mannheim.

Steiner, V. and Wagner, K. (1998) Has Earnings Inequality in Germany Changed in the 1980's? Zeitschrift für Wirtschafts- und Sozialwissenschaften, 118(1), 2959.

Weiler, A. (1997) Zwischen Angleichung und Differenzierung - Entwicklung geschlechtsspezifischer Entgeltstrukturen in Westdeutschland. WSI-Mitteilungen, 2, 126134. 